\title{
How Social Media-Enabled Communication Awareness Enhances Project Team Performance
}

\author{
Oliver Krancher \\ Institute of Information Systems \\ University of Bern \\ Engehaldenstr. 8 \\ 3012 Bern \\ Switzerland \\ oliver.krancher@iwi.unibe.ch \\ Jens Dibbern \\ Institute of Information Systems \\ University of Bern \\ Engehaldenstr. 8 \\ 3012 Bern \\ Switzerland \\ jens.dibbern@iwi.unibe.ch \\ Paul Meyer \\ Meyer Werft \\ Industriegebiet Süd \\ 26871 Papenburg \\ Germany \\ paul.meyer@meyerwerft.de
}

Published in 2018 in: Journal of the Association for Information Systems 19(9) (http://aisel.aisnet.org/jais/)

Copyright owned by the Association for Information Systems

For-profit use not allowed 


\title{
How Social Media-Enabled Communication Awareness En- hances Project Team Performance
}

\begin{abstract}
Project teams increasingly rely on computer-mediated communication. In this paper, we propose that communication within these teams benefits from a communication-awareness feature that summarizes communication at one common place. We argue that such a feature pays out specifically during action episodes, when team members engage in taskwork. We conducted two studies of 51 and 35 project teams to examine how the amount of communication during action episodes relates to team performance under low versus high communication awareness. In both studies, we technologically designed communication awareness as the availability of a feed, known from social media platforms, that displays all team-internal, computer-mediated communication. The results show that the communication-awareness feature makes communication during action episodes more beneficial, both in term of effectiveness and efficiency. Zooming into the temporal patterns of communication during action episodes further reveals that high-performing teams in the high-communication-awareness condition stick out by early and steady communication. Implications for current and future research on team communication and awareness support are discussed.
\end{abstract}

Keywords: Team communication, team episodes, awareness systems, communication awareness, social media platforms, team performance. 


\section{INTRODUCTION}

Project teams are a critical locus of innovation and adaptability in contemporary organizations (Chiocchio \& Essiembre, 2009; Hoegl \& Parboteeah, 2006). A key issue in project teams is communication. Communication plays an important role not only at the outset of projects, when it serves to define goals and strategies (Fussell et al., 1998; Mathieu \& Schulze, 2006), but also during subsequent action episodes, i.e., the time periods during which team members perform taskwork (Marks, Mathieu, \& Zaccaro, 2001). Communication during action episodes enables a variety of team processes that are critical to performance, such as monitoring progress, asking substantive questions, providing feedback, and coordinating subsequent actions (Humphrey \& Aime, 2014; LePine, Piccolo, Jackson, Mathieu, \& Saul, 2008; Marks et al., 2001; Salas, Sims, \& Burke, 2005). These team processes require teams to engage in steady, rather than one-time, communication in order to keep up with new insights, project progress, and shifts in available resource (Ilgen, Hollenbeck, Johnson, \& Jundt, 2005; Massey, MontoyaWeiss, \& Hung, 2003). However, establishing a steady stream of team communication during action episodes is often difficult due to multitasking (i.e., different members working on different tasks), part-time involvement (i.e., members devoting only part of their capacity to the project), and asynchronous collaboration (i.e., different members working at different times) (Marks et al., 2001; McGrath, 1991). Under these circumstances, team members may pay too little attention to their team members' communication, which may easily lead to slow response times and progress delays (Cummings, Espinosa, \& Pickering, 2009; McGrath, 1991; Ocker, Hiltz, Turoff, \& Fjermestad, 1995). In other words, even if team members attempt to communicate a lot, these attempts will be in vain if the team lacks awareness of the communication.

These communication difficulties are further aggravated if teams communicate over information and communication technology (ICT) (Galegher \& Kraut, 1994; Schweitzer \& Duxbury, 2010). For example, ICT mediation was found to reduce much needed communication (Alge, Wiethoff, 
\& Klein, 2003; De Guinea, Webster, \& Staples, 2012; Hinds \& Bailey, 2003), to decrease the team's motivation to engage in important team processes (Andres, 2012; Cramton, 2001), and to lead to dispersion of messages across multiple channels (Buder, 2007; Cramton, 2001). Given these difficulties, it is not surprising that research on ICT-mediated communication has struggled to find positive effects of team communication during action episodes on team performance (Kanawattanachai \& Yoo, 2007; Weisband, 2002). Thus, although communication can enable critical team processes during action episodes, empirical evidence from ICTmediated teams fails to reveal significant associations with team performance.

Our study seeks to contribute to resolving this inconclusive relationship between team communication during action episodes and team performance by integrating research on team communication with that on awareness systems. Awareness systems are ICT designed to increase the visibility of events or states important to the team (Bardram \& Hansen, 2010; Gutwin \& Greenberg, 2002; Yang, Tong, \& Teo, 2015). Specifically, we seek to integrate two findings from research on awareness systems. The first is that awareness systems can help teams to shift attention from individual taskwork to the needs of the team (Dehler, Bodemer, Buder, \& Hesse, 2009; Heath, Svensson, Hindmarsh, Luff, \& vom Lehn, 2002). Such attention shifting may help establish a steady stream of communication despite multitasking, part-time involvement, and low motivation to engage in team processes. The second finding is that project team members often find communication to be the most useful source of awareness information (Dabbish, Stuart, Tsay, \& Herbsleb, 2012; Gutwin, Penner, \& Schneider, 2004). Taken together, these two insights suggest that project teams can benefit from technology-enabled communication awareness (CA), i.e., ICT designed to increase the visibility of communication by making messages visible at a single place. Such syndication (Zhang, Venkatesh, \& Brown, 2011) of messages is one of the key properties of social media platforms (SMPs), which have rapidly diffused in contemporary organizations (MarketsandMarkets, 2017). SMPs enable CA 
by making the communication that is relevant to particular users, or teams, visible in feeds (Leonardi, 2014; Leonardi, Huysman, \& Steinfield, 2013). We argue that feeds help teams to maintain an overview over messages. Feeds may thereby stimulate team members to frequently shift their attention to team communication and to establish a steady stream of communication throughout action episodes. As a result, team communication during action episodes may be more effective and efficient.

Our paper examines these ideas by addressing the following research question: How does technology-enabled CA (implemented through the feed feature as known from SMPs) influence the effectiveness and the efficiency of project team communication? We report two studies in which small, ICT-supported project teams collaborated on particular tasks over several weeks. In each study, we manipulated CA through ICT design. Teams in the high-CA condition were provided with a feed that tied together team communication at one place, whereas teams in the low-CA condition lacked such a feed. In both studies, we found positive associations between task-oriented communication during action episodes and team performance (effectiveness, efficiency) only for teams provided with the feed. Hence, task-oriented communication during action episodes was beneficial only in concert with technology-enabled CA. To examine why only teams provided with a feed were able to excel through communication, we zoomed into their pacing of communication during action episodes. We found that high-performing teams provided with a feed stood out by early and steady communication, supporting the idea that the feed enables frequent attention shifting throughout action episodes. The key contribution of our study lies in theorizing and empirically demonstrating how technology-enabled CA, a key feature of SMPs, influences the effectiveness and efficiency of project team communication during particular collaboration episodes. In the remainder of this paper, we review the literatures on project team communication and awareness systems, develop hypotheses, describe the two studies, and discuss implications. 


\section{BACKGROUND LITERATURE}

\section{Communication in Project Teams}

Project Teams. A team is a "set of two or more people who interact, dynamically, interdependently, and adaptively toward a common and valued goal" (Salas, Dickinson, Converse, \& Tannenbaum, 1992, p. 4). Team research has recognized that "different types of teams ... manifest teamwork processes (e.g., communication) differently" (Salas et al., 2005, p. 562). A widely established taxonomy distinguishes project teams from work teams and management teams (Cohen \& Bailey, 1997). Project teams are teams that (1) are time limited, (2) produce unique output, and (3) progressively elaborate plans and ideas (Chiocchio \& Essiembre, 2009, pp. 390-391; Cohen \& Bailey, 1997, pp. 242-43). Progressive elaboration is a consequence of time-limitedness and uniqueness, and it has important implications for the dynamics of team processes, as Chiocchio and Essiembre (2009) argue: "It means that at the beginning of the project, there is only a broad understanding of the end result and the process used to achieve it. Work is planned as properly as possible at this stage, but as knowledge grows and the project progresses, both become more explicit and detailed" (p. 391).

Team episodes. Team research has acknowledged this dynamic nature of teams and incorporated the role of time into theories and research designs (Humphrey \& Aime, 2014; llgen et al., 2005). While some research has incorporated time by bracketing collaborations into two equally spaced time periods (Gersick, 1988, 1989; Kanawattanachai \& Yoo, 2007; Maruping, Venkatesh, Thatcher, \& Patel, 2015; Mathieu \& Schulze, 2006; Weisband, 2002), others have argued against fixed phase durations, submitting that team pacing varies according to task characteristics, multitasking behavior, individual attitudes towards time, and the available technology (Marks et al., 2001; Waller, Conte, Gibson, \& Carpenter, 2001; Waller, Zellmer-Bruhn, \& Giambatista, 2002). Marks et al. (2001) proposed an alternative framework based on the concept of episodes. Episodes are "distinguishable periods of time over which performance 
accrues" (p. 359). Important episodes in project teams include strategy formulation and action. Projects typically begin with strategy formulation, during which the team discusses expectations, relays task-related information, assigns roles and tasks, orders and times actions, and broadly defines how actions should be executed (Marks et al., 2001, p. 365). Strategy formulation is typically followed by action episodes, or "periods of time when teams are engaged in acts that contribute directly to goal accomplishment (i.e. taskwork)" (Marks et al., 2001, p. 360). Importantly, during action episodes, project teams engage not only in individual taskwork (i.e., members not only execute the work assigned to them) but also in team processes that serve to direct, align, and monitor taskwork (Marks et al., 2001, p. 357). Important team processes during action episodes include: monitoring progress (e.g. sharing information about task work progress), systems monitoring (e.g. monitoring the availability of team members), team monitoring and back-up behavior (e.g. providing feedback on a task, helping team members, assuming and completing tasks for them), and coordination (e.g. agreeing on the sequence and timing of subsequent actions) (Marks et al., 2001, p. 363). Although these team processes are, to a large extent, mediated by communication (Humphrey \& Aime, 2014; Marks et al., 2001), communication during action episodes is hampered by the distributed focus of attention due to multitasking (i.e., different team members working on different tasks). In concert with part-time involvement and asynchronous collaboration, distributed foci of attention may produce serious delays in team communication. As a result, teams may struggle to establish a steady stream of communication that would enable essential team processes to occur precisely when they are most needed.

Communication and Team Performance. In light of these communication difficulties, it comes at little surprise that empirical support for the positive effect of communication on team performance has so far been inconclusive. On the one hand, several studies demonstrated positive effects of communication on performance (e.g. Barrick, Bradley, Kristof-Brown, \& Colbert, 
2007; Espinosa, Nan, \& Carmel, 2015; Keller, 1994). On the other hand, some studies found insignificant effects of communication on the performance of project teams (Espinosa, Cummings, \& Pickering, 2012; He, Butler, \& King, 2007), or they found significant positive effects only for communication during early collaboration episodes (Kanawattanachai \& Yoo, 2007; Mathieu \& Schulze, 2006; Pearsall, Ellis, \& Bell, 2010; Weisband, 2002). The latter research established that communication during early episodes is important for performance because it allows teams to build shared mental models and communication structures that guide subsequent action (Gersick, 1988; Kanawattanachai \& Yoo, 2007; Mathieu \& Schulze, 2006; Mintzberg, Raisinghani, \& Théorêt, 1976; Pearsall et al., 2010; Weisband, 2002). Two studies explicitly compared communication during early and later episodes (Kanawattanachai \& Yoo, 2007; Weisband, 2002). Both studies found that positive associations of communication and team performance disappeared after the midpoint.

At first sight, these findings may appear puzzling. Although there is strong empirical evidence for the critical role of team processes during action episodes (e.g. sharing progress information, helping teammates, coordinating) (LePine et al., 2008), there is little support for the performance benefits of communication during action episodes. In light of these findings, some scholars have argued that communication loses its critical function for team processes during later collaboration episodes (Kanawattanachai \& Yoo, 2007, p. 789; Weisband, 2002, p. 324). While this is plausible in routine settings, it is difficult to imagine how project teams can achieve progressive elaboration without communication. A possible alternative explanation is that project teams struggle to communicate effectively given the challenges that project teams face during action episodes (multitasking, part-time involvement, asynchronous collaboration) and in using ICT-mediated communication (reduced communication, low motivation to engage in team processes, dispersion of messages across channels) (Andres, 2012; Cramton, 2001; De Guinea 
et al., 2012). Under these conditions, communication is likely to suffer from delays and misunderstandings (Cummings et al., 2009; McGrath, 1991). Thus, teams may be unable to benefit from team communication because they struggle to establish a steady stream of coherent and timely communication, which is essential for team processes to thrive within the limited time of the project. These difficulties may manifest in insignificant correlations between the amount of communication and performance.

Research on communication in teams also points to strategies that may help teams cope with these challenges. There is some evidence that communication can be beneficial if teams are provided with structures, such as fixed milestones, that accelerate the pacing of communication (Massey et al., 2003; Okhuysen \& Eisenhardt, 2002). Such structural guidance, however, leaves open the question how teams can enhance their effectiveness and efficiency of communication within action episodes, i.e. episodes flanked by preceding planning episodes and looming deadlines. To address this question, research on awareness systems directs us towards a possible answer.

\section{Awareness Systems}

There is a substantial body of research on awareness systems (see Table 1 for an overview of empirical work). Awareness systems are ICTs designed to increase the visibility of states or events (Markopoulos \& Mackay, 2009). Such enhanced visibility may support the team members' perception of states or events over time, the comprehension of the meaning of these states or events, and the projection of that information in the near future (Endsley, 1995, p. 36). As Table 1 shows (see column 2), researchers have examined ICT designed to promote awareness of a variety of states or events, such as the team members' activities, workload, communication, location, presence, participation, and knowledge. 
Table 1. Empirical Research on Awareness in Teams

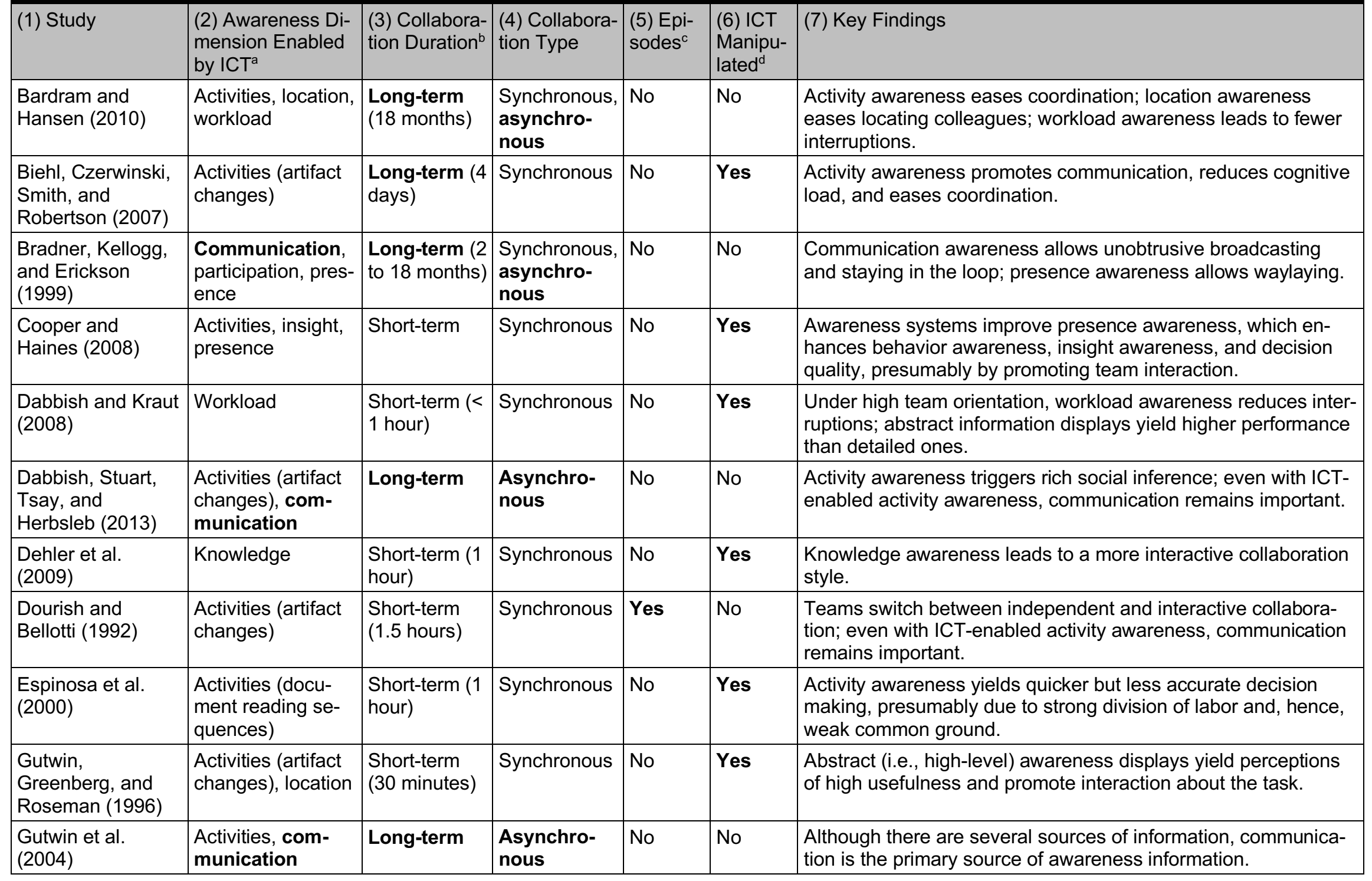




\begin{tabular}{|c|c|c|c|c|c|c|}
\hline (1) Study & $\begin{array}{l}\text { (2) Awareness Di- } \\
\text { mension Enabled } \\
\text { by ICT }\end{array}$ & $\begin{array}{l}\text { (3) Collabora- } \\
\text { tion Duration }\end{array}$ & $\begin{array}{l}\text { (4) Collabora- } \\
\text { tion Type }\end{array}$ & $\begin{array}{l}\text { (5) Epi- } \\
\text { sodes }^{\mathrm{C}}\end{array}$ & $\begin{array}{l}\text { (6) ICT } \\
\text { Manipu- } \\
\text { lated }^{\mathrm{d}}\end{array}$ & (7) Key Findings \\
\hline Heath et al. (2002) & Activities & Long-term & Synchronous & No & No & $\begin{array}{l}\text { People deliberately, subtly, and selectively create awareness of } \\
\text { their activities in order to trigger chains of social interaction. }\end{array}$ \\
\hline $\begin{array}{l}\text { Janssen, Erkens, } \\
\text { and Kirschner } \\
(2011)\end{array}$ & Participation & $\begin{array}{l}\text { Short-term (7 } \\
\text { hours) }\end{array}$ & Synchronous & No & No & $\begin{array}{l}\text { Longer awareness system use yields higher participation aware- } \\
\text { ness, more process-related communication, and more equal } \\
\text { participation. }\end{array}$ \\
\hline $\begin{array}{l}\text { Kimmerle and } \\
\text { Cress (2008) }\end{array}$ & Participation & Short-term & Synchronous & No & Yes & $\begin{array}{l}\text { Awareness of individual team members' participation yields } \\
\text { higher contributions by those team members that are concerned } \\
\text { about self-presentation. }\end{array}$ \\
\hline $\begin{array}{l}\text { Lowry and } \\
\text { Nunamaker (2003) }\end{array}$ & $\begin{array}{l}\text { Activities (artifact } \\
\text { changes) }\end{array}$ & $\begin{array}{l}\text { Short-term (4 } \\
\text { hours) }\end{array}$ & Synchronous & No & Yes & $\begin{array}{l}\text { Activity awareness yields higher amounts of negative and of } \\
\text { positive messages, higher effectiveness, and higher efficiency. }\end{array}$ \\
\hline $\begin{array}{l}\text { Malhotra and } \\
\text { Majchrzak (2014) }\end{array}$ & $\begin{array}{l}\text { Activities, pres- } \\
\text { ence }\end{array}$ & Long-term & $\begin{array}{l}\text { Synchronous, } \\
\text { asynchro- } \\
\text { nous }\end{array}$ & No & No & $\begin{array}{l}\text { Activity awareness is beneficial for project teams (non-routine } \\
\text { tasks); presence awareness is beneficial for teams with many } \\
\text { knowledge boundaries. }\end{array}$ \\
\hline $\begin{array}{l}\text { Omoronyia, } \\
\text { Ferguson, Roper, } \\
\text { and Wood (2009) }\end{array}$ & $\begin{array}{l}\text { Activities, partici- } \\
\text { pation }\end{array}$ & $\begin{array}{l}\text { Long-term }(6 \\
\text { weeks) }\end{array}$ & $\begin{array}{l}\text { Mostly asyn- } \\
\text { chronous }\end{array}$ & No & No & $\begin{array}{l}\text { Awareness information helps direct software developers' atten- } \\
\text { tion to the people, tasks, and artifacts that are most relevant to } \\
\text { their work. }\end{array}$ \\
\hline $\begin{array}{l}\text { Tran, Yang, and } \\
\text { Raikundalia (2009) }\end{array}$ & $\begin{array}{l}\text { Communication, } \\
\text { presence }\end{array}$ & $\begin{array}{l}\text { Short-term (2 } \\
\text { hours) }\end{array}$ & Synchronous & No & Yes & $\begin{array}{l}\text { Communication awareness yields shorter completion times and } \\
\text { fewer turns, presumably due to fewer clarification questions and } \\
\text { fewer repeated turns. }\end{array}$ \\
\hline $\begin{array}{l}\text { Treude and Storey } \\
(2010)\end{array}$ & Activities & Long-term & $\begin{array}{l}\text { Asynchro- } \\
\text { nous }\end{array}$ & No & No & $\begin{array}{l}\text { Activity awareness enables task prioritization, facilitates short- } \\
\text { term planning, and promotes competition. }\end{array}$ \\
\hline Yang et al. (2015) & Knowledge & Unknown & Synchronous & No & No & $\begin{array}{l}\text { Knowledge awareness is associated with greater task cohesion } \\
\text { and greater satisfaction. }\end{array}$ \\
\hline
\end{tabular}

a While terminology varies per study, we broadly distinguish awareness of activities (what others do), of communication (what other say), of insight (what others think), of knowledge (what others know), of location (where others are), of participation (how much others contribute), and of presence (whether others are present); ${ }^{b}$ short-term if the duration of the collaborations studied was shorter than one day; ${ }^{\mathrm{c}}$ indicates whether different episodes were distinguished during data analysis; ${ }^{\mathrm{d}}$ indicates whether technological conditions were manipulated by the researchers; in bold: research design characteristics shared with our studies 
Two sets of findings of awareness systems research are particularly notable in the context of our study. First, awareness systems can help teams shift attention from individual taskwork to the team and thereby stimulate collective activity (or teamwork) (Dehler et al., 2009; Heath et al., 2002; Schmidt, 2002). For instance, Dehler et al. (2009) found that teams provided with technology-enabled knowledge awareness excelled through an interactive approach, whereas teams without such technology support excelled through an individualistic approach. Biehl et al. (2007) observed higher amounts of communication (i.e., a type of collective activity) when teams were provided with activity awareness. Ethnographic research suggests an explanation for greater collective activity provoked by awareness (Heath et al., 2002; Schmidt, 2002). Under distributed foci of attention, awareness systems enable "appropriate obtrusiveness" (Schmidt, 2002, p. 292), i.e., they help frequently direct the team members' attention from individual taskwork to the team. This may help trigger and advance conversations at the right moment, such as when team members need help or when subsequent actions need to be coordinated.

Second, qualitative awareness systems research indicates that people often prefer communication as a source of awareness even if alternative information sources are available (Dabbish et al., 2013; Fussell et al., 1998; Gutwin et al., 2004). For instance, Gutwin et al. (2004) concluded from a qualitative study of distributed software development teams that "[a]lthough there are several sources of information, ... awareness is maintained primarily through text-based communication" (Gutwin et al., 2004, p. 72). In a similar setting, Dabbish et al. (2013) found that while in some cases, information from high-level awareness displays was sufficient, "[i]n many cases, [people] needed to directly communicate about a code contribution" because the "project vision" and the "reasoning behind a change or the organization of ... code ... was not always clear" (p. 40) from the displays. This indicates that team members often prefer rich, communication-based awareness information because it is most informative about "intentions and rationale" (Dabbish et al., 2013, p. 40) behind the team's actions. 
These two findings suggest that technology-enabled communication awareness (CA) can help project teams cope with the specific challenges of team communication during action episodes by steadily drawing the team members' attention to the needs of the team and thereby reducing delays and misunderstandings. This may enable a steady stream of communication and may help make communication more beneficial.

However, empirical support for these ideas is lacking because of three gaps in the awareness systems literature. First, although many scholars have examined displays providing activity awareness, relatively few (Bradner et al., 1999; Dabbish et al., 2013; Gutwin et al., 2004; Tran et al., 2009) have examined CA (see column 2). This is unfortunate given the qualitative findings about people's preference for communication-based awareness and given the increasing diffusion of ICT-supported CA through SMPs (Leonardi et al., 2013; MarketsandMarkets, 2017). Second, the literature lacks studies that technologically manipulated awareness in collaborations longer than a day. Some researchers manipulated ICT (see column 6 in Table 1) in short-term collaborations of few hours or less (see column 3). Yet, the difficulties in establishing a steady stream of communication are likely to be much less salient in short-term collaborations than in collaborations where members work on different task at different times over periods of several weeks and where they devote only a fraction of their time and attention to the project (McGrath, Arrow, Gruenfeld, Hollingshead, \& O'Connor, 1993). Other researchers studied longer collaborations (see column 3) but did not manipulate ICT (see column 6). Although these studies yielded important qualitative insights into the use of awareness systems, they were not designed to reveal statistically significant differences between distinct ICT conditions. Third, there is a dearth of research on the role of awareness systems during particular collaboration episodes (see column 5). Hence, awareness systems research has not yet explored the idea that technology-enabled awareness may play particular roles during particular collaboration episodes, such as during action episodes. 
In sum, our review of the literatures on team episodes, team communication and on awareness systems suggests that CA-enabled through ICT features that increase the visibility of communication-may help project teams cope with the specific challenges of communication during action episodes. However, whether and how such a feature makes communication during action episodes more beneficial remains an open empirical question.

\section{HYPOTHESES}

We build on the literatures on team episodes, team communication, and awareness systems to explain how ICT-enabled CA influences the effect of project team communication on team performance during action episodes. Specifically, we propose that the availability of a feed that draws together team communication at a single place makes team communication more effective and efficient. Figure 1 provides an up-front summary of our research model.

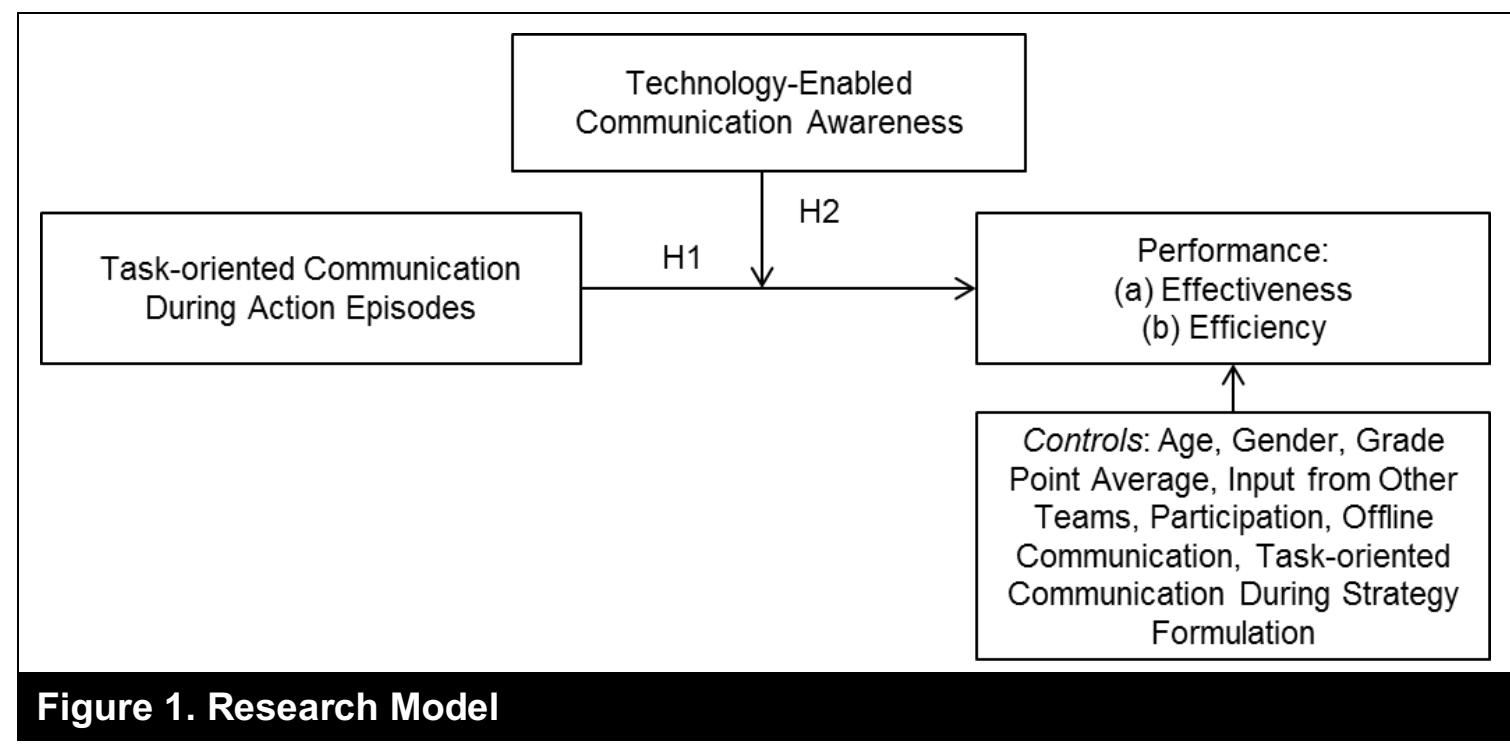

\section{Performance}

In line with prior team research (Dennis, Wixom, \& Vandenberg, 2001; Espinosa et al., 2000; Galegher \& Kraut, 1994; Gopal \& Gosain, 2010), we define performance in terms of two major dimensions: (1) effectiveness, defined as the degree to which the output delivered by a project 
team meets the requirements, and (2) efficiency, defined as the relation of a project team's output to input (i.e., effort) (Law, 2016). We focus on both dimensions because prior studies of ICT in team collaboration often obtained different results for these two performance dimensions (Espinosa et al., 2000; Galegher \& Kraut, 1994; Pridmore \& Phillips-Wren, 2011).

\section{Task-Oriented Communication During Action Episodes}

While the existing literature emphasizes the important role of communication in early team episodes, such as strategy formulation (Gersick, 1988; Kanawattanachai \& Yoo, 2007; Mathieu \& Schulze, 2006; Mintzberg et al., 1976; Pearsall et al., 2010; Weisband, 2002), we argue that communication also plays a critical role during action episodes. We submit that in particular task-oriented communication is critical during action episodes. Task-oriented communication denotes messages that are related to the substance of the task (e.g. substantive questions, feedback on work products) or to the process through which the task is accomplished (e.g. information on own past or current activities, suggestions for coordinating subsequent activities) (Fussell et al., 1998; Kanawattanachai \& Yoo, 2007; Marks et al., 2001). Task-oriented communication during action episodes enables a variety of team processes that have been shown to increase team performance, such as monitoring progress, team monitoring and backup behavior (which includes providing feedback), and coordination (LePine et al., 2008; Marks et al., 2001). We expect that teams that engage in greater amounts of task-oriented communication during action episodes are more effective because teams will be more able to leverage the knowledge of their members if they frequently ask substantive questions and provide feedback. Such teams are more likely to identify flaws in the emerging task products and to incorporate insights that team members gained over time, leading to output of higher quality. We also anticipate that it pays out for teams to engage in greater amounts of task-oriented communication in terms of efficiency, because teams are less likely to suffer from duplicated efforts if they frequently share progress information and explicitly coordinate actions. Moreover, team 
members who lack knowledge in a particular content domain save efforts if they pose questions to their teammates instead of expending large efforts in unproductive individual taskwork. We hypothesize:

H1a/b: The amount of task-oriented communication during action episodes is positively related to (a) effectiveness and (b) efficiency.

\section{Technology-Enabled Communication Awareness}

Although task-oriented communication during action episodes potentially enables a set of critical team processes, it is not granted that communication will actually serve these purposes. Communication will often suffer from serious delays given the challenges that project teams face during action episodes (distributed attention due to multitasking, part-time involvement, asynchronous collaboration) (Marks et al., 2001; McGrath, 1991) and in using ICT-mediated communication (reduced communication, low motivation to engage in team processes, dispersion of messages across channels) (Andres, 2012; Cramton, 2001; De Guinea et al., 2012). Because of these delays, communication may not enable team processes when most needed.

Technology-enabled CA may help alleviate these adverse circumstances. Specifically, we argue that the feed feature known from SMPs enhances CA (Leonardi, 2015; Leonardi et al., 2013). A feed automatically syndicates communication from various channels, such as from discussion boards and personal profiles, at a single spot in form of a summarized text including the publishing date and author (Leonardi et al., 2013; Zhang et al., 2011). Such feed-enabled communication awareness helps to frequently draw team members' attention from their individual taskwork to team communication. This can help establish a steady stream of task-oriented communication, allowing team processes to occur when they are needed, rather than in the last few days, when the looming project deadline directs the team members' attention to the project. As a consequence, task-oriented communication is likely to be more beneficial. 
Feed-enabled CA allows for more effective questioning and feedback processes, resulting in output of higher quality (i.e., higher effectiveness). Moreover, with more timely monitoring and coordination processes, teams are also likely to be more efficient, for example by avoiding duplication of effort. These benefits from feeds are, however, contingent on the teams' decisions to engage in task-oriented communication. If a team chooses not to engage in task-oriented communication, the feeds will not display any messages and hence will not draw the members' attention to the needs of the team. Conversely, if a team engages in high amounts of task-oriented communication, the feeds are particularly likely to turn the team members' attention to the varied ways in which members can contribute to ongoing conversations. We hypothesize:

H2a/b: The associations between the amount of task-oriented communication and performance (in terms of (a) effectiveness and (b) efficiency) are stronger (i.e. more positive) under high CA (i.e., when the feed feature is available).

While we hypothesize that feed-enabled CA helps make task-oriented communication during action episodes more effective, we do not expect a main effect of the mere availability of a feed on performance. As argued above, empty feeds are unlikely to turn the team members' attention to any needs of the team. Hence, the availability of the feed is likely to be beneficial only in concert with task-oriented communication during action episodes. This echoes the often articulated idea that particular ICT features create impact in concert with team behaviors that leverage the potential offered by the particular features (DeSanctis et al., 2008, p. 555; Kock \& Lynn, 2012; Malhotra \& Majchrzak, 2014; Niederman, Briggs, de Vreede, \& Kolfschoten, 2008). 


\section{METHODS}

\section{Research Design}

In order to test our hypotheses we conducted two studies with two slightly different contexts, notably with different team tasks and slightly different team size. Such "context-only extension" (Berthon, Pitt, Ewing, \& Carr, 2002) "serves to investigate the generalizability of ... research findings" (Berthon et al., 2002, p. 419).

Both studies were done with student teams. Notwithstanding the strengths of field research, student teams provided a number of advantages. First, we were able to manipulate the technology through which teams collaborated. Second, teams within the same study worked on the same task, which eased comparability. Third, students mostly lacked joint collaboration history, performed this type of task for the first time, and worked on projects in other courses at the same time. These conditions were consistent with characteristics that are essential or typical for project teams, such as time-limitedness, uniqueness of task for the team, and part-time involvement. Fourth, students are mostly familiar with leisure social media platforms such as Facebook. This reduced the effect of technology assimilation hurdles (Venkatesh, Morris, Davis, \& Davis, 2003), which were not the core interest of this study.

\section{Treatments}

In each study, we used the same two technological conditions, to which the teams were randomly assigned. Table 2 provides an overview. In the low-CA condition, teams were provided with a collaboration platform that offered the following broad capabilities: (1) communication (team forums, direct messages, document attentions, profile updates); (2) friend relationships (adding other people as friends); (3) artifact editor (integrated Google Docs $®$ word processor, spreadsheets, and diagrams). These capabilities are common to many contemporary collaboration platforms (Leonardi et al., 2013). In the high-CA condition, teams were provided with a 
collaboration platform that offered all capabilities of the low-CA condition and, in addition, CA through team feeds and individual feeds. Appendix A shows the user interfaces of the two platforms. We used two highly similar platforms that differed only in the CA feature to facilitate attributing differences to this particular feature.

\begin{tabular}{|c|c|c|c|}
\hline Capability & Features & Low CA & High CA \\
\hline Communication & $\begin{array}{l}\text { Team forums (accessible to team members only); di- } \\
\text { rect messages to team members, to the team, and to } \\
\text { other users; document annotations (i.e. comments } \\
\text { function) in word processor; user profiles including } \\
\text { photos and user information }\end{array}$ & \multicolumn{2}{|c|}{ Available } \\
\hline $\begin{array}{l}\text { Friend Relation- } \\
\text { ships }\end{array}$ & Adding users (from the same platform) as friends & \multicolumn{2}{|c|}{ Available } \\
\hline Artifact editor & $\begin{array}{l}\text { Concurrent editing of artifacts (Google Docs } ® \text { word } \\
\text { processor, spreadsheet calculations, drawing com- } \\
\text { ponents were integrated into the platform.) }\end{array}$ & \multicolumn{2}{|c|}{ Available } \\
\hline $\begin{array}{l}\text { Communication } \\
\text { awareness }\end{array}$ & $\begin{array}{l}\text { Team feeds (summaries of a team's communication, } \\
\text { visible to the team) and individual feeds (summaries } \\
\text { of an individual's communication, visible to the team } \\
\text { and to friends); feeds include: } \\
\text { - system-generated notifications on forum posts } \\
\text { - system-generated notifications on profile updates } \\
\text { - } \begin{array}{l}\text { user-generated feed posts (updates on artifact ac- } \\
\text { tions, status updates) }\end{array}\end{array}$ & $\begin{array}{c}\text { Not } \\
\text { available }\end{array}$ & Available \\
\hline
\end{tabular}

\section{Participants and Tasks}

Table 3 provides an overview of the participants, teams, and tasks of the two studies. Compared to study 2 , study 1 involved slightly larger teams (team size of 4 in study 1 vs. 3 in study 2), more teams (51 vs. 35 ), a shorter collaboration duration ( 3 weeks versus 5 weeks), and a different task (solving a business process improvement problem versus a knowledge management problem). We removed three teams from study 1 and three teams from study 2 because of lack of participation (five teams) or technical problems (one team). The appendices B and C provide more information on the task material of the two studies. In both studies, we randomly assigned participants to teams. 


\begin{tabular}{|c|c|c|}
\hline & Study 1 & Study 2 \\
\hline Participants & $\begin{array}{l}\text { Students in a compulsory undergrad- } \\
\text { uate course on business process } \\
\text { management at a Swiss university }\end{array}$ & $\begin{array}{l}\text { Students in an elective undergradu- } \\
\text { ate course on knowledge manage- } \\
\text { ment systems at the same university } \\
\text { as in study } 1\end{array}$ \\
\hline Team size & 4 & 3 \\
\hline $\begin{array}{l}\text { Number of teams in } \\
\text { final sample }\end{array}$ & 51 (204 participants) & 35 (105 participants) \\
\hline Average age & 22 & 23 \\
\hline$\%$ female & $37 \%$ & $41 \%$ \\
\hline $\begin{array}{l}\% \text { major in busi- } \\
\text { ness administration }\end{array}$ & $89 \%$ & $73 \%$ \\
\hline Task & $\begin{array}{c}\text { Business process improvement } \\
\text { problem (process mapping, cycle } \\
\text { time and cost analysis, identifying } \\
\text { improvements) }\end{array}$ & $\begin{array}{l}\text { Knowledge management problem } \\
\text { (develop recommendations for de- } \\
\text { sign and implementation of a } \\
\text { knowledge management system) }\end{array}$ \\
\hline $\begin{array}{l}\text { Artifact editor to be } \\
\text { used for task }\end{array}$ & \begin{tabular}{|c|} 
Word, spreadsheets (for cycle time \\
and cost analysis), drawing (for pro- \\
cess mapping)
\end{tabular} & Word \\
\hline Duration & 3 weeks & 5 weeks \\
\hline
\end{tabular}

\section{Procedures}

At the outset, the participants had one week of time to familiarize themselves with the platform.

During that period, the participants provided demographic information in a pre-questionnaire, watched a video of a duration of 10 minutes that introduced them to the platform, and then obtained personal credentials to access the platform. Although the participants were informed that they were allowed to meet physically, they were encouraged to use the platform as much as possible, and they were able to access the case material and the shared artifacts through the platform only. Moreover, the participants were informed that they were allowed to exchange information with members from other teams assigned to the same platform. This was supposed to make our study setting more realistic, given that members of real organizations would typically communicate not only within but also across teams through SMPs (Leonardi, 2015). 
After the one-week familiarization period, the participants had three weeks in study 1 , and five weeks in study 2, to complete the task. The five weeks in study 2 included a 10-days spring break. After these periods, the platform was frozen and the participants were invited to respond to a post-questionnaire. The team deliverables were graded by an assessor who was neither a member of the research team nor the platform administrator. There were different assessors in study 1 and study 2 . The grading criteria of study 1 included the correctness and completeness of the process model, of the calculations, and of the process improvement suggestions. The grading criteria of study 2 considered the identification of knowledge management problems from the case, the choice of appropriate theoretical frameworks, the mapping of the framework to case information, and specification of recommendations for actions consistent with the framework.

\section{Measures and Coding Procedure}

Our measurement approach combined data from different sources: data extracted from the collaboration platform, the grading scores awarded by assessors, pre- and post-surveys, and grade point average (GPA) scores obtained from the university's internal records. To measure the amount of task-oriented communication during action episodes, we extracted all team-internal messages (i.e., direct messages, forum posts, feed updates, document annotations) from the platform and performed two steps of content analysis (Krippendorff, 2012). First, we coded for each message whether the message was task oriented. A message was coded as task oriented when it referred to the substance of the task (e.g. substantive questions, feedback on work products) or to the process through which the task was accomplished (e.g. information on own past or current activities, suggestions for coordinating subsequent activities). Each message was coded by two coders, who were blind to the hypotheses of the study. Inter-coder agreement was 96\% (Cohen's kappa: .74), supporting the reliability of the coding procedure (Landis \& Koch, 1977). Second, in order to separate communication during strategy formulation 
from communication during action episodes, we coded, for each team, the day on which the team had concluded strategy formulation. This day was determined based on the day of the last message that served to negotiate the team strategy. Each team was coded by two coders blind to the hypotheses. Cronbach's alpha was .94 , supporting the reliability of the coding procedure. Appendix D provides coding examples.

Table 4 shows our measures. We examined two performance variables, effectiveness and efficiency. Our effectiveness measure was the grading score that the assessors awarded based on the team deliverables. Efficiency, i.e., "the ability ... to produce the maximum output ... with the minimum of time, effort, and other inputs" (Law, 2016), was measured as the standardized grading score minus the standardized effort that the team invested into taskwork (i.e., the time spent on actions in the artifact editor). Efficiency was thus highest when teams obtained high scores with low taskwork effort. Similar measurement approaches have been used in other settings in which efficiency is of interest (Paas, Tuovinen, Tabbers, \& Van Gerven, 2003). Taskoriented communication during action was measured as the amount of messages that (1) were team internal, (2) were task oriented, and (3) were sent after initial strategy formulation.

We controlled for a number of variables to help rule out alternative explanations (see also Table 4). First, we controlled for task-oriented communication during strategy formulation (i.e., before action episodes) to substantiate our claim that communication only during action episodes benefits from CA. Second, we controlled for a set of individual differences (age, gender, and GPA) that could potentially correlate both with the amount of communication and with performance. Third, since our measures of task-oriented communication referred to communication over the platform only, we controlled for offline communication, i.e., the amount of communication outside the platform, such as through email, phone, and face-to-face meetings. Fourth, we controlled for whether a team received input from other teams. This served to rule out the explanation that teams assigned to different platforms might differ in the degree to which they seek 
and obtain help from other teams. Fifth, we controlled for participation, i.e. the degree to which task-oriented communication during action was equally distributed across team members. We controlled for participation because some studies suggest that awareness systems may affect participation (Cooper \& Haines, 2008; De Dreu \& West, 2001; Janssen et al., 2011).

\begin{tabular}{|c|c|}
\hline \multicolumn{2}{|c|}{ Dependent, independent, and moderating variables } \\
\hline Effectiveness & Grading score (scale: 0 to 100 ) assigned by assessor of team deliverables \\
\hline Efficiency & $\begin{array}{l}\text { Grading score (standardized) minus taskwork effort (standardized); to meas- } \\
\text { ure taskwork effort we extracted the start time and end time of all artifact edit- } \\
\text { ing actions from the platform }\end{array}$ \\
\hline $\begin{array}{l}\text { Communication } \\
\text { Awareness }\end{array}$ & $\begin{array}{l}1 \text { if the team was assigned to the high-CA condition (collaboration platform } \\
\text { with feeds), else } 0 \text { (collaboration platform without feeds) }\end{array}$ \\
\hline $\begin{array}{l}\text { Task-oriented com- } \\
\text { munication during } \\
\text { action }\end{array}$ & $\begin{array}{l}\text { The number of task-oriented team-internal messages that were sent over the } \\
\text { platform after initial strategy formulation }\end{array}$ \\
\hline \multicolumn{2}{|l|}{ Control variables } \\
\hline $\begin{array}{l}\text { Task-oriented com- } \\
\text { munication during } \\
\text { strategy formulation }\end{array}$ & $\begin{array}{l}\text { The number of task-oriented team-internal messages that were sent over the } \\
\text { platform until the last day of initial strategy formulation }\end{array}$ \\
\hline Age & Average age of team members according to pre-questionnaire \\
\hline Gender & Fraction of female team members according to pre-questionnaire \\
\hline Grade Point Average & $\begin{array}{l}\text { Average GPA of all team members based on the university's records; the GPA } \\
\text { excluded the grade obtained on the course in which the study was embedded }\end{array}$ \\
\hline $\begin{array}{l}\text { Offline Communica- } \\
\text { tion }\end{array}$ & $\begin{array}{l}\text { Average of three items from post-questionnaire adapted from Ma and Agarwal } \\
(2007) \text { (Cronbach's alpha: .94, items provided in Appendix E) }\end{array}$ \\
\hline $\begin{array}{l}\text { Input from Other } \\
\text { Teams }\end{array}$ & $\begin{array}{l}1 \text { if the team has received input from other teams according to communication } \\
\text { records, else } 0 \text { (coded based on communication data extracted from platform) }\end{array}$ \\
\hline Participation & $\begin{array}{l}\text { Herfindahl index of the distribution of task-oriented communication during ac- } \\
\text { tion over team members; high numbers indicate high concentration and, thus, } \\
\text { unequal participation (e.g. one team member making most contributions) }\end{array}$ \\
\hline
\end{tabular}

\section{Regression and Post-hoc Analysis}

We relied on ordinary least squares (OLS) regression to test our hypotheses, using a threestep hierarchical regression strategy. In the first step (model 1), we included only control variables. In the second step (model 2), we added the main effects of CA and task-oriented communication during action. In the third step (model 3a), we added the hypothesized interaction 
of $\mathrm{CA}$ and task-oriented communication during action. To substantiate our claim that communication only during action episodes benefits from CA, we estimated the alternative model 3b, which included an interaction between CA and task-oriented communication during strategy formulation. We ran all models separately for study 1 , for study 2 , and for the pooled dataset (i.e., for data pooled from study 1 and study 2 ). In all models, we applied a square root transformation to task-oriented communication during strategy formulation and to task-oriented communication during action in order to eliminate the positive skew of these count data variables. Moreover, we standardized the data before pooling. We performed a number of checks to ascertain that the assumptions of OLS were met (Wooldridge, 2009, pp. 104-105). Histograms and q-q plots showed that the residuals of all models followed normal distributions, indicating that the assumption of normally distributed error terms was met. Variance inflation factors were below 3 , suggesting that multicollinearity problems were not salient in the data. Plotting residuals and dependent variables in a scatter plot diagram showed no departure from the assumption of homoscedastic error terms.

After the regression analyses, we performed two post-hoc analyses. The first post-hoc analysis served to shed light on our claim that differences in pacing between technological conditions (i.e., earlier and steadier communication in the high-CA condition) explain differences in the effectiveness and efficiency of task-oriented communication during action. To shed light on pacing, we examined two sets of indicators. First, we divided action episodes by their midpoint and measured the amount and fraction of communication during the first half. High amounts and fractions in the first half indicate relatively early communication. To increase robustness, we performed the analysis for two types of midpoints: midpoints by time and midpoints by amounts of messages. Midpoints by time were the average mean day of action episodes. Midpoints by amount of messages were the day by which all teams had sent, on average, at least 
half of their task-oriented communication during action ${ }^{1}$. Second, we calculated the number of days during action episodes on which messages were sent. High numbers of days indicate relatively steady communication. In the second post-hoc analysis, we examined whether higher taskwork efficiency in the high-CA condition was due to substitution of taskwork effort by communication effort. To examine this explanation, we compared the total length of messages, a proxy for communication efforts, between conditions.

\section{RESULTS}

\section{Descriptive Statistics and Regression Results}

Table 5 shows descriptive statistics per platform and study. Moreover, the last column shows the means in the pooled data (i.e., the combined dataset of both studies). The only significant differences between technological conditions were un-hypothesized differences in efficiency. In study 1 and in the pooled dataset, teams in the high-CA condition were significantly more efficient than teams in the low-CA condition ( $\mathrm{t}$ test, $\mathrm{p}<.05$ ). In study 2 , teams in the high-CA condition were also more efficient than teams in the low-CA condition, but this difference was not statistically significant. There were no significant differences between platforms along other dimensions, such as in the amount of task-oriented communication during action. Table 6 and Table 7 show bi-variate correlations. Table 8 shows the regression results of the models predicting effectiveness. Table 9 shows the regression results of the models predicting efficiency.

\footnotetext{
${ }^{1}$ For instance, in study 1 , the average last day of strategy formulation according to our coding was day 10. Hence, the average start day of action episodes was day $11(10+1)$. The last full day of collaboration was day 21 . The midpoint by time was day $16((11+21) / 2)$. Conversely, the midpoint by amount of messages was day 18 because it was only by day 18 that teams had sent at least half of their communication during action $(567$, or $53 \%$, out of 1077 messages were sent by day 18.).
} 


\begin{tabular}{|c|c|c|c|c|c|c|}
\hline \multirow[b]{2}{*}{ Variable } & \multicolumn{2}{|c|}{ Study $1^{a}$} & \multicolumn{2}{|c|}{ Study $2^{a}$} & \multicolumn{2}{|c|}{ Pooled Datab } \\
\hline & Low CA & High CA & Low CA & High CA & Low CA & High CA \\
\hline Effectiveness & $71.3(11.1)$ & $71.8(13.3)$ & $58.9(15.3)$ & $63.2(15.5)$ & -.07 & .07 \\
\hline Efficiency & $-.30 *(1.12)$ & $.34^{*}(1.03)$ & $-.24(1.15)$ & $.23(1.20)$ & $-.25^{*}$ & $.25^{*}$ \\
\hline Age & $22.3(1.1)$ & $22.3(.9)$ & $23.5(2.21)$ & $23.7(2.3)$ & -.03 & .03 \\
\hline Gender & $.38(.28)$ & $.34(.19)$ & $.43(.28)$ & $.36(.27)$ & .10 & -.10 \\
\hline GPA & $4.70(.20)$ & $4.66(.24)$ & $4.56(.26)$ & $4.74(.26)$ & -.08 & .08 \\
\hline Input from Other Teams & $.81(.40)$ & $.80(.41)$ & $.65(.49)$ & $.67(.49)$ & .00 & .00 \\
\hline Offline Communication & $3.92(1.79)$ & $4.27(1.63)$ & $3.67(1.66)$ & $3.64(1.73)$ & -.06 & .06 \\
\hline Participation & $.34(.08)$ & $.32(.05)$ & $.37(.15)$ & $.46(.17)$ & -.02 & .02 \\
\hline ToC During Stat. Formul. & $14.1(7.7)$ & $13.0(4.7)$ & $9.5(6.8)$ & $11.2(4.0)$ & -.06 & .06 \\
\hline ToC During Action & $18.7(11.2)$ & $22.6(14.6)$ & $17.9(14.2)$ & $14.6(9.9)$ & -.05 & .05 \\
\hline$n$ & 26 & 25 & 17 & 18 & 43 & 43 \\
\hline
\end{tabular}

(ToC: Task-oriented Communication; a study 1, study 2: figures show means and standard deviations; ${ }^{\mathbf{b}}$ pooled data: figures means that have been standardized for each study; *difference between low and high CA significant at $p<.05$ )

\begin{tabular}{|l|r|r|l|r|r|r|l|l|l|l|l|}
\hline & \multicolumn{1}{|c|}{$\begin{array}{l}\text { Table 6. Correlations (Study 1) } \\
\text { tiven. }\end{array}$} & $\begin{array}{l}\text { Effi- } \\
\text { ciency }\end{array}$ & Age & $\begin{array}{l}\text { Gen- } \\
\text { der }\end{array}$ & GPA & Input & Offl. & Part. & $\begin{array}{l}\text { ToC } \\
\text { SF }\end{array}$ & CA & $\begin{array}{l}\text { ToC } \\
\text { Act. }\end{array}$ \\
\hline Effectiveness & 1.00 & & & & & & & & & & \\
\hline Efficiency & $.55^{*}$ & 1.00 & & & & & & & & & \\
\hline Age & $.34^{*}$ & .01 & 1.00 & & & & & & & & \\
\hline Gender & .00 & $-.28^{*}$ & .22 & 1.00 & & & & & & & \\
\hline GPA & .27 & .19 & -.08 & -.14 & 1.00 & & & & & & \\
\hline Input & -.01 & -.08 & -.02 & .07 & .14 & 1.00 & & & & & \\
\hline Offline Com. & -.23 & -.27 & .04 & .11 & -.26 & .04 & 1.00 & & & & \\
\hline Participation & -.20 & -.27 & -.01 & .12 & -.16 & .05 & .18 & 1.00 & & & \\
\hline ToC SF & -.16 & -.12 & .08 & $.40^{*}$ & .01 & .09 & -.01 & .15 & 1.00 & & \\
\hline CA & .02 & $.29^{*}$ & .01 & -.07 & -.09 & -.01 & .10 & -.15 & -.05 & 1.00 & \\
\hline ToC Action & $.40^{*}$ & .05 & .05 & .10 & .02 & .20 & .00 & -.15 & -.17 & .15 & 1.00 \\
\hline
\end{tabular}

(ToC SF: Task-oriented Communication During Strategy Formulation, CA: Communication Awareness, ToC Action: Task-oriented Communication During Action, ${ }^{*} p<.05$ ) 


\begin{tabular}{|l|r|r|r|r|r|l|l|l|l|l|l|}
\hline Table 7. Correlations (Study 2) & $\begin{array}{l}\text { Effec- } \\
\text { tiven. }\end{array}$ \\
\hline ciency & Age & $\begin{array}{l}\text { Gen- } \\
\text { der }\end{array}$ & GPA & Input & Offl. & Part. & $\begin{array}{l}\text { ToC } \\
\text { SF }\end{array}$ & CA & $\begin{array}{l}\text { ToC } \\
\text { Act. }\end{array}$ \\
\hline Effectiveness & 1.00 & & & & & & & & & & \\
\hline Efficiency & $.59^{*}$ & 1.00 & & & & & & & & & \\
\hline Age & .27 & .28 & 1.00 & & & & & & & & \\
\hline Gender & $.38^{*}$ & .26 & .33 & 1.00 & & & & & & & \\
\hline GPA & -.16 & -.03 & $-.39^{*}$ & $-.34^{*}$ & 1.00 & & & & & & \\
\hline Input & -.15 & -.26 & .15 & .17 & $-.45^{*}$ & 1.00 & & & & & \\
\hline Offline Com. & .15 & .06 & .12 & .28 & .06 & -.10 & 1.00 & & & & \\
\hline Participation & -.09 & -.06 & $-.43^{*}$ & -.32 & $.34^{*}$ & -.28 & -.09 & 1.00 & & & \\
\hline ToC SF & .18 & -.20 & -.18 & -.05 & .19 & .19 & .24 & .18 & 1.00 & & \\
\hline CA & .14 & .20 & .05 & -.13 & .32 & .02 & -.01 & .28 & .22 & 1.00 & \\
\hline ToC Action & .22 & -.06 & -.04 & .16 & .00 & -.16 & -.08 & .04 & -.15 & -.08 & 1.00 \\
\hline
\end{tabular}

(ToC SF: Task-oriented Communication During Strategy Formulation, CA: Communication Awareness, ToC Action: Task-oriented Communication During Action, ${ }^{*} \mathrm{p}<.05$ )

$\mathrm{H} 1 \mathrm{a} / \mathrm{b}$ predicted positive associations between task-oriented communication during action and the two performance dimensions, effectiveness (a) and efficiency (b). We refer to model 2 in testing these hypotheses. Table 8 shows significant positive associations between task-oriented communication during action and effectiveness in study $1(\beta=.37, p<.01)$, in the pooled dataset $(\beta=.31, p<.01)$, but not in study $2(\beta=.18, p>.05)$. Thus, $\mathrm{H} 1 \mathrm{a}$ is partially supported. Table 9 fails to show significant associations between task-oriented communication during action and efficiency in study $1(\beta=.02, p>.05)$, in study $2(\beta=-.16, p>.05)$, or in the pooled dataset $(\beta=-.04, p>.05)$. Hence, $\mathrm{H} 1 \mathrm{~b}$ is not supported.

$\mathrm{H} 2 \mathrm{a} / \mathrm{b}$ predicted a positive interaction effect of $\mathrm{CA}$ on the association between task-oriented communication during action and performance. We refer to model $3 a$ in testing these hypotheses. Table 8 shows significant positive interaction effects relative to effectiveness in study 1 ( $\beta$ $=.40, p<.05)$, in study $2(\beta=.52, p<.05)$, and in the pooled dataset $(\beta=.34, p<.05)$. Table 9 shows significant positive interaction effects relative to efficiency in study $1(\beta=.46, p<.01)$, in study $2(\beta=.59, \mathrm{p}<.05)$, and in the pooled dataset $(\beta=.41, \mathrm{p}<.01)$. Thus, $\mathrm{H} 2 \mathrm{a}$ and $\mathrm{H} 2 \mathrm{~b}$ are supported in both studies. 


\begin{tabular}{|c|c|c|c|c|c|c|c|c|c|c|c|c|}
\hline \multirow[b]{2}{*}{ Variables } & \multicolumn{4}{|c|}{ Study 1} & \multicolumn{4}{|c|}{ Study 2} & \multicolumn{4}{|c|}{ Pooled Data } \\
\hline & Model 1 & Model 2 & $\begin{array}{c}\text { Model } \\
3 a^{a}\end{array}$ & $\begin{array}{c}\text { Model } \\
3 \mathbf{b}^{\mathrm{a}}\end{array}$ & Model 1 & Model 2 & Model 3a $a^{a}$ & Model $3 b^{a}$ & Model 1 & Model 2 & $\begin{array}{c}\text { Model } \\
3 a^{a}\end{array}$ & $\begin{array}{c}\text { Model } \\
3 b^{a}\end{array}$ \\
\hline Intercept & $.00(.13)$ & $.00(.12)$ & $.00(.12)$ & $.00(.12)$ & $.00(.15)$ & $.00(.15)$ & $.00(.14)$ & $.00(.15)$ & $.00(.10)$ & $.00(.10)$ & $.00(.10)$ & $.00(.10)$ \\
\hline Age & $.36^{* *}(.13)$ & $.36^{* *}(.12)$ & $.41^{* *}(.12)$ & $.35^{\star *}(.13)$ & $.21(.19)$ & $.14(.19)$ & $.07(.18)$ & $.14(.19)$ & $.30^{* *}(.11)$ & $.31^{* *}(.11)$ & $.32^{* *}(.10)$ & $.30^{* *}(.11)$ \\
\hline Gender & $.07(.15)$ & $-.01(.14)$ & $.05(.14)$ & $-.01(.14)$ & $.35(.18)$ & $.31(.18)$ & $.33(.17)$ & $.29(.19)$ & $.14(.11)$ & $.08(.11)$ & $.11(.11)$ & $.08(.11)$ \\
\hline GPA & $.25(.14)$ & $.25(.13)$ & $.26^{*}(.12)$ & $.24(.13)$ & $-.21(.20)$ & $-.31(.21)$ & $-.41(.20)$ & $-.29(.21)$ & $.17(.11)$ & $.15(.11)$ & $.16(.10)$ & $.14(.10)$ \\
\hline Input Other Teams & $-.02(.13)$ & $-.10(.13)$ & $-.08(.12)$ & $-.10(.13)$ & $-.42^{*}(.19)$ & $-.44^{*}(.20)$ & $-.63^{* *}(.21)$ & $-.41(.20)$ & $-.09(.11)$ & $-.11(.10)$ & $-.15(.10)$ & $-.10(.10)$ \\
\hline Offline Comm. & $-.17(.14)$ & $-.16(.13)$ & $-.13(.12)$ & $-.16(.13)$ & $-.09(.18)$ & $-.06(.17)$ & $-.18(.17)$ & $-.05(.18)$ & $-.09(.11)$ & $-.08(.10)$ & $-.11(.10)$ & $-.08(.10)$ \\
\hline Participation & $-.11(.14)$ & $-.05(.13)$ & $-.10(.13)$ & $-.07(.13)$ & $-.01(.19)$ & $-.10(.19)$ & $.06(.19)$ & $-.11(.19)$ & $-.10(.11)$ & $-.09(.10)$ & $-.05(.10)$ & $-.11(.10)$ \\
\hline ToC SF & $-.20(.14)$ & $-.11(.14)$ & $-.10(.13)$ & $-.06(.16)$ & $.38^{*}(.18)$ & $.37(.18)$ & $.41^{*}(.17)$ & $.44^{*}(.20)$ & $-.03(.11)$ & $.04(.11)$ & $.05(.11)$ & $.13(.13)$ \\
\hline $\mathrm{CA}$ & & $-.01(.13)$ & $-.01(.12)$ & $-.02(.13)$ & - & $.25(.18)$ & $.24(.17)$ & $.26(.18)$ & & .05 (.10) & .05 (.10) & $.05(.10)$ \\
\hline ToC Action & - & $.37^{* *}(.13)$ & $.06(.19)$ & $.35^{*}(.14)$ & - & $.18(.16)$ & $-.18(.23)$ & .18 . .16$)$ & - & $.31^{* *}(.10)$ & $.08(.14)$ & $.28^{* *}(.10)$ \\
\hline ToC Action $\times$ CA & - & & $.40 *(.18)$ & & - & & $.52^{*}(.24)$ & - & - & - & $.34^{*}(.13)$ & \\
\hline ToC SF $\times$ CA & - & - & - & $-.10(.15)$ & - & - & - & $-.16(.19)$ & - & - & & $-.18(.12)$ \\
\hline Adjusted $\mathrm{R}^{2}$ & .17 & .27 & .33 & .26 & .17 & .20 & .30 & .19 & .08 & .17 & .22 & .18 \\
\hline $\mathrm{R}^{2}$ & .28 & .40 & .46 & .41 & .34 & .41 & .50 & .43 & .16 & .25 & .31 & .28 \\
\hline$\Delta \mathrm{R}^{2}$ & .28 & .12 & .06 & .01 & .34 & .07 & .09 & .02 & .16 & .09 & .06 & .02 \\
\hline$F$ & $2.41^{*}$ & $3.06^{* *}$ & $3.47^{\star *}$ & $2.76^{*}$ & 1.98 & 1.92 & $2.43^{*}$ & 1.78 & 2.11 & $2.87^{* *}$ & $3.42^{* \star}$ & $2.86^{* *}$ \\
\hline F Change & $2.41^{*}$ & $4.11^{*}$ & $4.69^{*}$ & .41 & 1.98 & 1.47 & $4.55^{*}$ & .68 & 2.11 & $4.80^{*}$ & $6.47^{*}$ & 2.35 \\
\hline
\end{tabular}

(ToC SF: Task-Oriented Communication During Strategy Formulation; CA: Communication Awareness; ToC Action: Task-Oriented Communication During Action; standardized coefficients shown; standard errors in parentheses, ${ }^{a}$ model comparisons contrast model $3 \mathrm{a}$ to model 2 and model $3 \mathrm{~b}$ to model $\left.2,{ }^{*} p<.05,{ }^{* *} p<.01,{ }^{* * *} p<.001\right)$ 


\begin{tabular}{|c|c|c|c|c|c|c|c|c|c|c|c|c|}
\hline \multirow[b]{2}{*}{ Variables } & \multicolumn{4}{|c|}{ Study 1} & \multicolumn{4}{|c|}{ Study 2} & \multicolumn{4}{|c|}{ Pooled Data } \\
\hline & Model 1 & Model 2 & $\begin{array}{c}\text { Model } \\
3 a^{a}\end{array}$ & $\begin{array}{c}\text { Model } \\
3 b^{\mathrm{a}}\end{array}$ & Model 1 & Model 2 & Model $3 a^{a}$ & $\begin{array}{c}\text { Model } \\
3 b^{\mathrm{a}}\end{array}$ & Model 1 & Model 2 & $\begin{array}{c}\text { Model } \\
3 a^{a}\end{array}$ & $\begin{array}{c}\text { Model } \\
3 b^{\mathrm{a}}\end{array}$ \\
\hline Intercept & $.00(.14)$ & $.00(.13)$ & $.00(.13)$ & $.00(.13)$ & $.00(.17)$ & $.00(.16)$ & $.00(.15)$ & $.00(.17)$ & $.00(.11)$ & $.00(.10)$ & $.00(.10)$ & $.00(.10)$ \\
\hline Age & $.08(.14)$ & $.07(.14)$ & $.13(.13)$ & $.07(.14)$ & $.26(.20)$ & $.14(.21)$ & $.07(.19)$ & $.14(.21)$ & $.14(.11)$ & $.12(.11)$ & $.13(.11)$ & $.11(.11)$ \\
\hline Gender & $-.24(.16)$ & $-.22(.15)$ & $-.15(.15)$ & $-.22(.16)$ & $.26(.20)$ & $.30(.20)$ & $.33(.18)$ & $.30(.20)$ & $-.03(.12)$ & $.01(.12)$ & $.05(.11)$ & $.01(.12)$ \\
\hline GPA & $.09(.15)$ & $.12(.14)$ & $.13(.14)$ & $.12(.15)$ & $.02(.22)$ & $-.11(.23)$ & $-.23(.22)$ & $-.11(.23)$ & $.11(.11)$ & $.09(.11)$ & $.1(.11)$ & $.09(.11)$ \\
\hline Input Other Teams & $-.06(.14)$ & $-.07(.14)$ & $-.05(.13)$ & $-.07(.14)$ & $-.30(.21)$ & $-.40(.21)$ & $-.62^{\star *}(.22)$ & $-.39(.22)$ & $-.15(.11)$ & $-.15(.11)$ & $-.19(.10)$ & $-.15(.11)$ \\
\hline Offline Comm. & $-.19(.15)$ & $-.22(.14)$ & $-.19(.14)$ & $-.22(.14)$ & $-.05(.19)$ & $-.05(.19)$ & $-.19(.18)$ & $-.05(.19)$ & $-.11(.11)$ & $-.13(.11)$ & $-.16(.10)$ & $-.13(.11)$ \\
\hline Participation & $-.19(.14)$ & $-.13(.14)$ & $-.18(.14)$ & $-.13(.15)$ & $.06(.20)$ & $-.03(.21)$ & $.15(.21)$ & $-.04(.21)$ & $-.15(.11)$ & $-.15(.11)$ & $-.11(.10)$ & $-.16(.11)$ \\
\hline ToC SF & $.00(.15)$ & $.01(.15)$ & $.02(.15)$ & $.00(.18)$ & $-.09(.20)$ & $-.13(.19)$ & $-.09(.18)$ & $-.10(.22)$ & $-.09(.11)$ & $-.12(.11)$ & $-.10(.11)$ & $-.08(.13)$ \\
\hline CA & - & $.28^{*}(.14)$ & $.28^{*}(.13)$ & $.28(.14)$ & - & $.30(.19)$ & $.30(.18)$ & $.31(.20)$ & - & $.27^{*}(.11)$ & $.27^{*}(.10)$ & $.27(.11)$ \\
\hline ToC Action & - & $.02(.14)$ & $-.34(.21)$ & $.02(.15)$ & - & $-.16(.17)$ & $-.57^{*}(.24)$ & $-.16(.18)$ & - & $-.04(.11)$ & $-.31^{*}(.14)$ & $-.05(.11)$ \\
\hline ToC Action $\times$ CA & - & - & $.46^{*}(.20)$ & & - & - & $.59 *(26)$ & - & - & - & $.41^{* *}(.14)$ & - \\
\hline ToC SF $\times$ CA & - & - & - & $.00(.17)$ & - & & - & $-.07(.21)$ & & - & - & $-.08(.13)$ \\
\hline Adjusted $\mathrm{R}^{2}$ & .06 & .11 & .19 & .09 & .02 & .07 & .21 & .04 & .03 & .08 & .16 & .07 \\
\hline $\mathrm{R}^{2}$ & .19 & .27 & .35 & .27 & .23 & .32 & .44 & .32 & .11 & .18 & .26 & .18 \\
\hline$\Delta \mathrm{R}^{2}$ & .19 & .08 & .08 & .00 & .23 & .09 & .12 & .00 & .11 & .07 & .08 & .00 \\
\hline$F$ & 1.46 & 1.68 & $2.18^{*}$ & 1.47 & 1.12 & 1.30 & 1.89 & 1.14 & 1.35 & 1.81 & $2.64^{* *}$ & 1.65 \\
\hline F Change & 1.46 & 2.16 & $5.17^{*}$ & .00 & 1.12 & 1.71 & $5.25^{\star}$ & .10 & 1.34 & $3.16^{*}$ & $8.57^{* *}$ & .42 \\
\hline
\end{tabular}

(ToC SF: Task-Oriented Communication During Strategy Formulation; CA: Communication Awareness; ToC Action : Task-Oriented Communication During Action Episodes; standardized coefficients shown; standard errors in parentheses, ${ }^{\text {a }}$ model comparisons contrast model $3 a$ to model 2 and model $3 b$ to model $\left.2,{ }^{*} p<.05,{ }^{* *} p<.01,{ }^{* * *} p<.001\right)$ 
Two sets of results deserve further attention. First, across both studies and both dependent variables, model fit was highest in model 3a-the model that includes the interaction of CA and task-related communication during action (effectiveness: $R^{2}$ of .46 in study 1 and of .50 in study 2; efficiency: $R^{2}$ of .35 in study 1 , and of .44 in study 2 ). Moreover, the differences in model fit between model 2 and model 3a were statistically significant $(F$ test, $p<.05$ for both studies and both dependent variables) and substantial (effectiveness: $\Delta R^{2}$ of .06 in study 1 and of .09 in study 2; efficiency: $\Delta R^{2}$ of .08 in study 1 and of .12 in study 2). Conversely, adding a term for the interaction of task-oriented communication during strategy formulation and performance from model 2 to model $3 \mathrm{~b}$ did not yield significant increases in model fit relative to model 2 in any study. Hence, the regression results demonstrate substantial positive interaction effects of CA with task-oriented communication during action but not with task-oriented communication during strategy formulation. Second, the regression results show a significant main effect of CA on efficiency in study $1(\beta=.28, p<.05)$ and in the pooled dataset $(\beta=.27, p<.05)$. Hence, overall, teams assigned to the high-CA condition achieved a given level of output quality with lower taskwork effort than teams assigned to the low-CA condition.

\section{Interaction Plots}

Figure 2 and Figure 3 illustrate the regression results through interaction plots. Figure 2 shows the relationship of task-oriented communication during action and effectiveness for teams assigned to different conditions (low CA vs. high CA). The plots show relatively flat slopes for teams assigned to the low-CA condition (see the lines marked by squares). The slope was marginally positive in study 1 (left-hand side of Figure 2) and marginally negative in study 2 (right-hand side of Figure 2). The relatively flat slopes indicate that the effectiveness of teams in the low-CA condition hardly depended on their amount of task-oriented communication during action episodes. Conversely, the plots show steep positive slopes for teams assigned to the high-CA condition (see the lines marked by triangles), both in study 1 and in study 2 . This 
suggests that, in both studies, only teams assigned to the high-CA condition were able to achieve high effectiveness with high amounts of task-oriented communication during action.

Figure 3 shows the relationships of task-oriented communication during action and efficiency. The plots show negative slopes for teams assigned to the low-CA condition (see the lines marked by squares) both in study 1 (left-hand side) and in study 2 (right-hand side). Hence, the more teams in the low-CA condition engaged in task-oriented communication during action, the less efficient they were. Conversely, the lines marked by triangles show positive slopes for teams assigned to the high-CA condition. Hence, teams in the high-CA condition were more efficient when they engaged in greater amounts of task-oriented communication during action. Interestingly, the Figure 3 shows that teams with low amounts of task-oriented communication during action were about similarly efficient on both platforms. The overall difference in efficiency between technological conditions stemmed, hence, from teams that engaged in high amounts of task-oriented communication. These teams were by far more efficient when they were assigned to the high-CA condition.
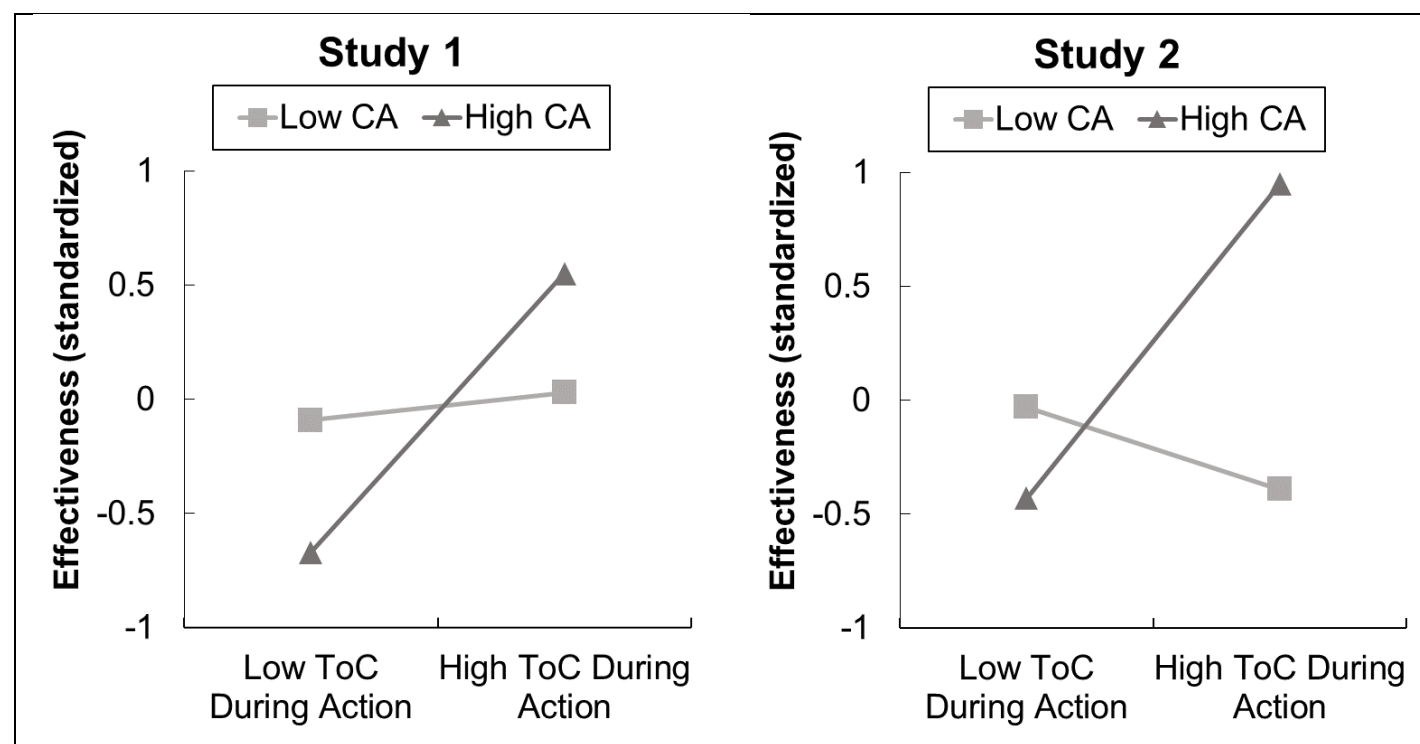

Figure 2. Interaction Plots Related to Effectiveness (ToC: Task-oriented Communication, low/high ToC refer to 1 SD below/above the sample mean) 

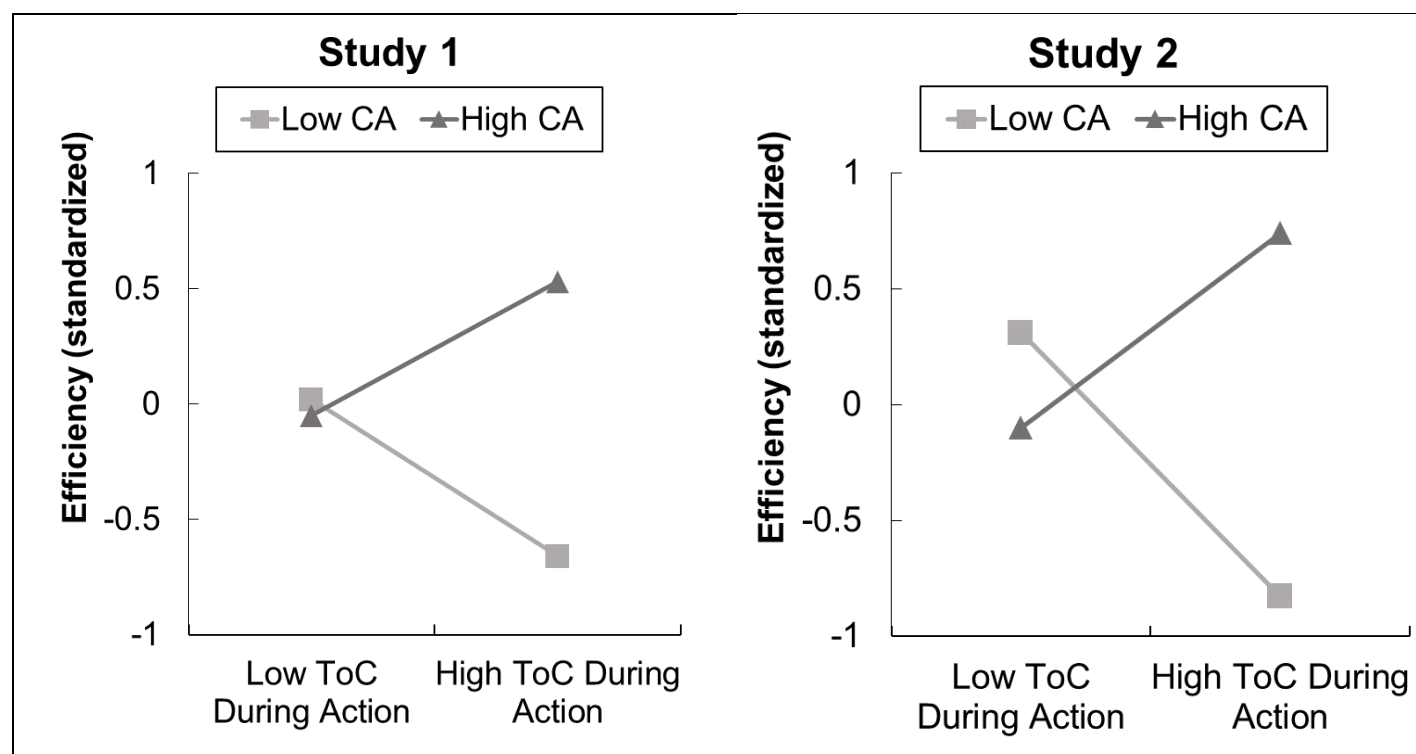

\section{Figure 3. Interaction Plots Related to Efficiency (ToC: Task-oriented} Communication)

\section{Post-hoc Analysis: Pacing of Task-oriented Communication During Action}

The preceding analysis suggests that only teams in the high-CA condition were able to achieve high performance through task-oriented communication. We performed a first post-hoc analysis to examine how their task-oriented communication during action was distinctive from that of other teams. Because our theorizing points to the role of pacing, we compared a set of pacing indicators between different technological conditions and different performance levels. We divided the sample into low-performing and high-performing teams, where high-performing teams were teams with effectiveness greater than the median of each study.

Table 10 presents the results for study 1 (top segment of the table), study 2 (mid segment of the table), and the pooled data (bottom segment of the table). In each segment, the first row shows the overall amount of messages that referred to task-oriented communication during action. There were no significant differences in this overall amount of messages between technological conditions within each performance group. In contrast, we noted several significant 
differences in the subsequent rows, which focus on the pacing of communication. The significant differences all referred to high-performing teams.

A number of indicators show that high-performing teams in the high-CA condition engaged in earlier task-oriented communication during action than high-performing teams in the low-CA condition. Specifically, high-performing teams in the high-CA condition sent greater absolute amounts of messages in the first half of the collaboration than high-performing teams in the low-CA condition (see the second and third row in each segment). For instance, in study 1 , high-performing teams in the high-CA condition sent 11.9 messages until the midpoint by time, whereas high-performing teams in the low-CA condition sent only 4.7 messages within this period. The differences in amount of messages in the first half were statistically significant for study 1 and the pooled data $(p<.05$, Mann-Whitney Test). In study 2 , high-performing teams in the high-CA condition sent more messages in the first half than high-performing teams in the low-CA condition, but the differences were not significant. High-performing teams in the highCA condition also sent greater relative amounts of messages in the first half of the collaboration than high-performing teams in the low-CA condition (see the fourth and fifth row in each segment). For example, in study 1 , high-performing teams in the high-CA condition sent, on average, $42 \%$ of their task-oriented communication during action until the midpoint by time, whereas high-performing teams in the low-CA condition sent only $19 \%$ within in this period. These differences were statistically significant for midpoints by time in study 1 , and for midpoints by time and by amount of messages in the pooled data ( $p<.05$, Mann-Whitney Test). 


\begin{tabular}{|c|c|c|c|c|c|c|c|c|c|}
\hline \multirow[b]{2}{*}{ Indicator } & \multicolumn{3}{|c|}{$\begin{array}{c}\text { Low-Performing } \\
\text { Teams (Low Ef- } \\
\text { fectiveness) }\end{array}$} & \multicolumn{3}{|c|}{$\begin{array}{l}\text { High-Performing } \\
\text { Teams (High Ef- } \\
\text { fectiveness) }\end{array}$} & \multicolumn{3}{|c|}{ All Teams } \\
\hline & $\begin{array}{c}\text { Low } \\
\text { CA }\end{array}$ & $\begin{array}{c}\text { High } \\
\text { CA }\end{array}$ & $\Delta$ & $\begin{array}{c}\text { Low } \\
\text { CA }\end{array}$ & $\begin{array}{c}\text { High } \\
\text { CA }\end{array}$ & $\Delta$ & $\begin{array}{c}\text { Low } \\
\text { CA }\end{array}$ & $\begin{array}{c}\text { High } \\
\text { CA }\end{array}$ & $\Delta$ \\
\hline Study 1 & $n=14$ & $n=12$ & & $n=12$ & $n=13$ & & $n=26$ & $n=25$ & \\
\hline ToC during action (no. of messages) & 18.0 & 16.1 & -1.9 & 19.6 & 28.5 & 9.0 & 18.7 & 22.6 & 3.8 \\
\hline $\begin{array}{l}\text { ToC during action (no. of messages) until ac- } \\
\text { tion episode midpoint by time }\end{array}$ & 6.1 & 5.7 & -0.5 & 4.7 & 11.9 & $7.2^{*}$ & 5.5 & 8.9 & 3.5 \\
\hline $\begin{array}{l}\text { ToC during action (no. of mess.) until action } \\
\text { episode midpoint by amount of messages }\end{array}$ & 9.1 & 9.0 & -0.1 & 8.3 & 17.3 & $9.0^{*}$ & 8.8 & 13.3 & 4.6 \\
\hline $\begin{array}{l}\text { Fraction of ToC during action until action epi- } \\
\text { sode midpoint by time }\end{array}$ & $46 \%$ & $35 \%$ & $-11 \%$ & $19 \%$ & $42 \%$ & $23 \% *$ & $33 \%$ & $38 \%$ & $5 \%$ \\
\hline $\begin{array}{l}\text { Fraction of ToC during action until action epi- } \\
\text { sode midpoint by amount of messages }\end{array}$ & $62 \%$ & $55 \%$ & $-7 \%$ & $35 \%$ & $60 \%$ & $25 \%$ & $50 \%$ & $57 \%$ & $7 \%$ \\
\hline Number of days with ToC during action & 6.3 & 5.6 & -0.7 & 5.3 & 7.0 & $1.7^{*}$ & 5.8 & 6.3 & .5 \\
\hline Study 2 & $n=10$ & $n=9$ & & $n=7$ & $n=9$ & & $n=17$ & $n=18$ & \\
\hline ToC during action (no. of messages) & 7.3 & 6.1 & -1.2 & 9.4 & 7.5 & -1.9 & 8.2 & 6.8 & -1.3 \\
\hline $\begin{array}{l}\text { ToC during action (no. of messages) until ac- } \\
\text { tion episode midpoint by time }\end{array}$ & 5.2 & 3.2 & -2.0 & 6.7 & 7.7 & 1.0 & 5.8 & 5.4 & -.4 \\
\hline $\begin{array}{l}\text { ToC during action (no. of mess.) until action } \\
\text { episode midpoint by amount of messages }\end{array}$ & 6.2 & 5.7 & -.5 & 10.7 & 13.4 & 2.7 & 8.1 & 9.6 & 1.5 \\
\hline $\begin{array}{l}\text { Fraction of ToC during action until action epi- } \\
\text { sode midpoint by time }\end{array}$ & $40 \%$ & $17 \%$ & $-23 \%$ & $31 \%$ & $37 \%$ & $6 \%$ & $37 \%$ & $27 \%$ & $-9 \%$ \\
\hline $\begin{array}{l}\text { Fraction of ToC during action until action epi- } \\
\text { sode midpoint by amount of messages }\end{array}$ & $48 \%$ & $35 \%$ & $-13 \%$ & $60 \%$ & $73 \%$ & $13 \%$ & $53 \%$ & $54 \%$ & $2 \%$ \\
\hline Number of days with ToC during action & 4.5 & 3.9 & -.6 & 4.1 & 6.6 & 2.4 & 4.4 & 5.2 & .9 \\
\hline $\begin{array}{l}\text { Pooled data (standardized values expect for } \\
\text { percentages) }\end{array}$ & $n=24$ & $n=21$ & & $n=19$ & $n=22$ & & $n=43$ & $n=43$ & \\
\hline $\begin{array}{l}\text { ToC during action (standardized no. of mes- } \\
\text { sages) }\end{array}$ & -.12 & -.39 & -.27 & .08 & .43 & .35 & -.03 & .03 & .06 \\
\hline $\begin{array}{l}\text { ToC during action (standardized no. of mes- } \\
\text { sages) until action episode midpoint by time }\end{array}$ & -.10 & -.25 & -.15 & -.14 & .47 & $.61^{*}$ & -.12 & .12 & .23 \\
\hline $\begin{array}{l}\text { ToC during action (standardized no. of mes- } \\
\text { sages) until action episode midpoint by } \\
\text { amount of messages }\end{array}$ & -.24 & -.28 & -.04 & -.09 & .61 & $.70^{*}$ & -.18 & .18 & .35 \\
\hline $\begin{array}{l}\text { Fraction of ToC during action until action epi- } \\
\text { sode midpoint by time }\end{array}$ & $44 \%$ & $27 \%$ & $-17 \%$ & $23 \%$ & $40 \%$ & $17 \% *$ & $35 \%$ & $34 \%$ & $-1 \%$ \\
\hline $\begin{array}{l}\text { Fraction of ToC during action until action epi- } \\
\text { sode midpoint by amount of messages }\end{array}$ & $56 \%$ & $47 \%$ & $-9 \%$ & $44 \%$ & $65 \%$ & $21 \% *$ & $51 \%$ & $56 \%$ & $5 \%$ \\
\hline Number of days with ToC during action & .01 & -.25 & -.26 & -.28 & .48 & $.76^{*}$ & -.12 & .12 & .24 \\
\hline
\end{tabular}

(ToC: Task-oriented communication, $\Delta$ : High-CA teams minus low-CA teams, *difference between highCA and low-CA teams statistically significant at $p<.05$ ) 
The figures also show that high-performing teams in the high-CA condition engaged in steadier task-oriented communication during action than high-performing teams in the low-CA condition, as indicated by the number of days on which messages were sent (see the last row in each segment). For example, in study 1, high-performing teams in the high-CA condition sent messages on 7.0 distinct days, whereas high-performing teams in the low-CA condition sent messages on only 5.3 distinct days. These differences were statistically significant in study 1 and in the pooled data ( $p<.05$, Mann-Whitney Test). In study 2, high-performing teams in the highCA condition also sent messages on more days (6.6 versus 4.1) than high-performing teams in the low-CA condition, although the difference was not statistically significant.

Table 10 shows no significant differences between technological conditions among low-performing teams (see the columns on the left-hand side) and in the overall sample (i.e., teams that are not separated by performance, see columns on the right-hand side).

Although the preceding analysis compared teams of different effectiveness levels, the analysis of teams of different efficiency levels yielded qualitatively similar results. These results are shown in Appendix F.

The results from this post-hoc analysis provide a refined perspective on the role of pacing. Teams in the high-CA condition did not universally engage in earlier or steadier task-oriented communication during action than teams in the low-CA condition. Instead, it appears that teams in the high-CA condition were more able to benefit from early and timely communication than teams in the low-CA condition. Only in the high-CA condition was a pattern of early and steady task-oriented communication associated with high performance. This suggests the refinement of our research model shown in Figure 4. Technology-enabled CA makes task-oriented communication during action episodes more beneficial only if the pacing of this communication is characterized by earliness and steadiness. 


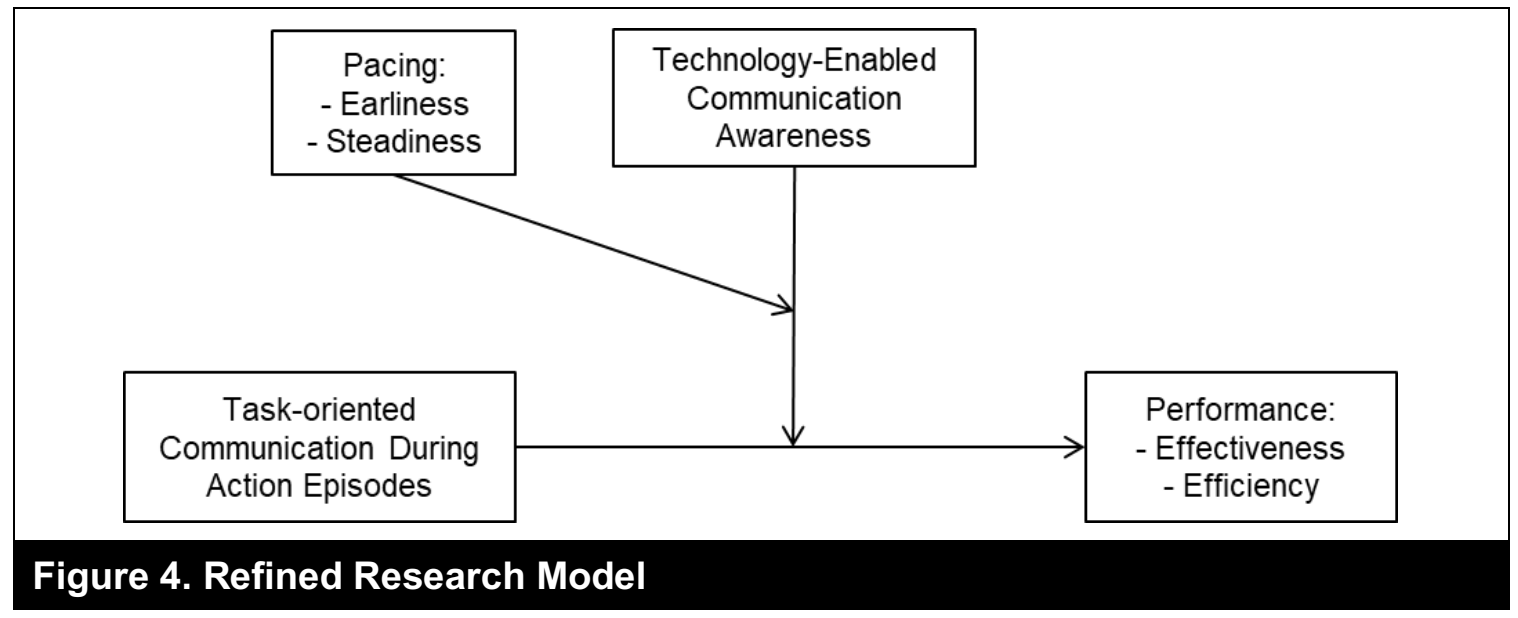

\section{Post-hoc Analysis: Effort}

An unexpected finding was that teams in the high-CA condition were overall more efficient than teams in the low-CA condition, a difference that was significant in study 1 and in the pooled data. We performed a second post-hoc analysis to scrutinize this finding. We examined whether teams in the high-CA condition had merely substituted taskwork effort (i.e., effort for editing shared artifacts), which was the focus of our efficiency measure, by communication effort (i.e., effort for sending task-oriented communication during action), which was not captured by our efficiency measure. The total number of characters of all task-oriented communication messages during action is a reasonable proxy for this communication effort. The higher the overall number of characters, the more time does it take team members to write and read these messages. Table 11 shows taskwork effort and communication effort (measured through the proxy of number of characters) for different performance groups and studies. The results were highly consistent across performance groups and studies. Indicators of communication effort were lower, not higher, in the high-CA condition. For instance, in study 1 , teams in the high-CA condition spent not only lower taskwork efforts than teams in the low-CA condition (19.2 instead of 25.4 hours) but also somewhat lower communication efforts as indicated by the total length of messages $(5,450$ instead of 5,928 characters). These numbers corroborate our assertion that 
teams in the high-CA condition were overall more efficient than teams in the low-CA condition. Importantly, although teams in the high-CA condition reaped greater benefits from task-oriented communication during action than teams in the low-CA condition, they did not appear to spend greater efforts on it.

\begin{tabular}{|l|r|r|r|r|r|r|r|r|r|}
\hline & \multicolumn{7}{|c|}{$\begin{array}{c}\text { Low-Performing } \\
\text { Teams (Low Effec- } \\
\text { tiveness) }\end{array}$} & $\begin{array}{c}\text { High-Performing } \\
\text { Teams (High Effec- } \\
\text { tiveness) }\end{array}$ & \multicolumn{3}{c|}{ All Teams } \\
\hline Indicator & $\begin{array}{c}\text { Low } \\
\text { CA }\end{array}$ & $\begin{array}{c}\text { High } \\
\text { CA }\end{array}$ & $\boldsymbol{\Delta}$ & $\begin{array}{c}\text { Low } \\
\text { CA }\end{array}$ & $\begin{array}{c}\text { High } \\
\text { CA }\end{array}$ & $\Delta$ & $\begin{array}{c}\text { Low } \\
\text { CA }\end{array}$ & $\begin{array}{c}\text { High } \\
\text { CA }\end{array}$ & $\Delta$ \\
\hline Study 1 & $n=14$ & $n=12$ & & $n=12$ & $n=13$ & & $n=26$ & $n=25$ & \\
\hline $\begin{array}{l}\text { Taskwork effort (artifact editing in } \\
\text { hours) }\end{array}$ & 23.1 & 15.4 & -7.8 & 28.0 & 22.8 & -5.2 & 25.4 & 19.2 & $-6.2^{*}$ \\
\hline $\begin{array}{l}\text { Communication effort (no. of charac- } \\
\text { ters of ToC during action) }\end{array}$ & 4659 & 4083 & -576 & 7409 & 6713 & -696 & 5928 & 5450 & -478 \\
\hline Study 2 & $n=10$ & $n=9$ & & $n=7$ & $n=9$ & & $n=17$ & $n=18$ & \\
\hline $\begin{array}{l}\text { Taskwork effort (artifact editing in } \\
\text { hours) }\end{array}$ & 7.3 & 6.1 & -1.2 & 9.4 & 7.5 & -1.9 & 8.2 & 6.8 & -1.3 \\
\hline $\begin{array}{l}\text { Communication effort (no. of charac- } \\
\text { ters of ToC during action) }\end{array}$ & 5272 & 3082 & -2190 & 6422 & 5141 & -1281 & 5745 & 4112 & -1633 \\
\hline Pooled data & $n=24$ & $n=21$ & & $n=19$ & $n=22$ & & $n=43$ & $n=43$ & \\
\hline $\begin{array}{l}\text { Taskwork effort (artifact editing in } \\
\text { hours, standardized) }\end{array}$ & .03 & -.47 & -.50 & .44 & .03 & -.41 & .21 & -.21 & $-.43^{*}$ \\
\hline $\begin{array}{l}\text { Communication effort (no. of charac- } \\
\text { ters of ToC during action, std.) }\end{array}$ & -.09 & -.40 & -.30 & .38 & .16 & -.22 & .11 & -.11 & -.23 \\
\hline
\end{tabular}

(ToC: Task-oriented communication, $\Delta$ : High-CA teams minus low-CA teams, * difference between high$\mathrm{CA}$ and low-CA teams statistically significant at $\mathrm{p}<.05$ )

\section{DISCUSSION}

In this research, we set out to study how technology-enabled communication awareness (CA) influences the effectiveness and efficiency of project team communication during action episodes. Two underlying motivations were: (1) the ambiguity of empirical results regarding the association between the amount of team communication during action episodes and team performance and (2) the lack of research that examines how technology-enabled CA affects collaboration during particular episodes of projects longer than few hours. To gain insight into these issues, we drew on research on team episodes, team communication, and awareness 
systems. The results of two studies yielded two sets of key findings. First, technology-enabled CA strengthens the relationships between task-oriented communication during action episodes and team performance (effectiveness, efficiency). Second, high-performing teams in the highCA conditions stand out by early and steady task-oriented communication during action. We discuss the implications of these findings for research on team communication and on awareness systems.

\section{Theoretical Implications}

\section{Research on Team Communication}

Although there is reason to believe that frequent communication during action episodes (e.g. in form of helping and coordinating each other) is critical for team performance (LePine et al., 2008), studies have failed to find significant associations between communication during later collaboration episodes and team performance (Kanawattanachai \& Yoo, 2007; Weisband, 2002). This raises the question of why the performance of project teams should not depend on their communication during action episodes. Project teams rely on the progressive elaboration of ideas and plans over time (Chiocchio \& Essiembre, 2009); thus why should more communication after initial planning not pay out? In this paper, we advance the idea that beyond the sheer amount of team communication during action episodes, it is the awareness of this communication that matters. Specifically, we argue that as far as communication in teams is increasingly computer mediated, it is technology-enabled communication awareness that matters. The results from our two studies provide support for this idea. We found only partial support for a positive relationship between task-oriented communication during action and team performance that would hold irrespective of technological conditions (see our mixed results on $\mathrm{H} 1 \mathrm{a} / \mathrm{b})$. However, we were able to demonstrate strong positive associations between task-oriented communication during action and team performance in those teams that were equipped 
with technology-enabled communication awareness (see our results on $\mathrm{H} 2 \mathrm{a} / \mathrm{b}$ and the interaction plots). Extending common views in the communication literature (Kanawattanachai \& Yoo, 2007; Weisband, 2002), this suggests that teams can strongly benefit from task-oriented communication during later collaboration periods if they use ICT that addresses the needs of the collaboration episode, in particular a feed that helps teams cope with the distributed foci of attention characteristic of action episodes. More broadly, our results suggest that findings on team communication that were obtained under a single ICT-supported condition (Espinosa et al., 2015; Kanawattanachai \& Yoo, 2007; Weisband, 2002) need not necessarily transfer to alternative ICT conditions, even if the differences between the ICT conditions are subtle, such as the availability of a feed. We therefore join a recent call by Malhotra and Majchrzak (2014) to incorporate greater variance in the type of ICT support into research on team communication.

\section{Research on Awareness Systems}

Our paper also contributes to awareness systems research by addressing three critical gaps in this literature. First and foremost, our study is among the first to demonstrate statistically significant support for the key idea of the attention-drawing perspective that technology-enabled awareness facilitates collective action by turning individuals' attention to the team (Dabbish et al., 2013; Dehler et al., 2009; Heath et al., 2002; Schmidt, 2002).

In both of our two studies, we found that teams were able to excel through task-oriented communication (i.e., a collective activity, being constituted by the interaction of members) only if provided with technology-enabled awareness. This collective avenue to high effectiveness in the high-CA condition contrasts with a rather individualistic avenue to high effectiveness in the low-CA condition. Although teams in the low-CA condition were also able to achieve high effectiveness, they achieved this not by leveraging team communication but by spending substantially higher efforts on taskwork (see our results on efficiency and Table 11). In contrast to 
communication, taskwork is individual activity. It "describes functions that individuals must perform to accomplish the team's task, whereas teamwork describes the interaction of team members" (Mathieu, Maynard, Rapp, \& Gilson, 2008, p. 420, emphasis added). We argue that teams in the low-CA condition relied on this individualistic approach because they lacked the ICT support required to leverage a collective (teamwork-based) approach. The attention-drawing perspective is further informed by our analysis of pacing. We found that high-performing teams in the high-CA condition stood out by early and steady communication. Endorsing an attention-drawing perspective, we argue that technology-enabled awareness frequently directs the attention of these individuals to their team, inviting them to ongoingly trigger and respond to conversations (Heath et al., 2002; Schmidt, 2002). In line with these ideas, those teams that leveraged the action potential for early and steady communication offered by the platform (i.e., teams that were in the high-CA condition and engaged in early and frequent communication) were precisely those teams that benefited most from task-oriented communication (high-performing teams in the high-CA condition, see our first post-hoc analysis). In conclusion, our findings provide support for the so far untested assertion that awareness systems help transform individualistic into more collective activity.

A second gap in the awareness systems literature is its scant attention to CA, notably at a time when technology-enabled CA is rapidly diffusing in contemporary organizations through SMPs. Our paper is among the first to provide statistically significant evidence of the specific ways in which technology-enabled CA shapes asynchronous project team collaboration. We show that technology-enabled CA enhances the effectiveness and efficiency of project team communication. Moreover, it allows teams to benefit from a rhythm of early and steady communication. These findings are somewhat related to Bradner and colleagues' qualitative observation that CA allows unobtrusive broadcasting and staying in the loop (Bradner et al., 1999; Erickson \& Kellogg, 2000). Our findings add that although technology-enabled CA may be less intrusive 
than, for instance, phone calls, it may enable "appropriate obtrusiveness" (Schmidt, 2002, p. 292). It draws others' attention to conversations and stimulates them to participate. In this sense, technology-enabled CA is more than an unobtrusive means for broadcasting and staying informed; it is a means subtly attracting team members' attention and for triggering and advancing conversations with them at the right moment.

Last but not least, a third gap in awareness systems research is its scant attention to the needs associated with particular collaboration episodes. Indeed, it is difficult to find awareness systems research that theorized or empirically examined distinct collaboration episodes. Our study is a first step in this direction. By drawing on research on team episodes, we argue that action episodes with their distributed foci of attention and multitasking pose challenges that are distinct from, for instance, those of strategy formulation, where teams have a shared focus on developing one team strategy. We argue that technology-enabled CA, which draws individuals' attention to the team, helps teams cope with these specific challenges of action episodes. Our studies provide support for these ideas. We found strong interaction effects of technology-enabled CA with task-oriented communication during action (see our results on model 3a) but not with task-oriented communication during strategy formulation (see our results on model $3 b$ ). Our study contributes thus to a more fine-grained understanding of what types of awareness support are beneficial to teams at what stage.

Finally, we believe that our unique study design was instrumental to these three contributions. While awareness systems researchers have rarely manipulated technological conditions in collaborations longer than a day, we conducted two studies of multi-week collaborations in which we manipulated awareness features and were able to replicate key findings. 


\section{Limitations and Directions for Future Research}

We acknowledge several limitations, which provide opportunities for future research. First, we did not implement dependencies between team members such as by providing single members with exclusive information (Okhuysen \& Eisenhardt, 2002). As a result, team members might have been able to circumvent the need for communication. This may explain why teams in the low-CA condition were also able to achieve high effectiveness through other means than communication, such as by individually expending high amounts of taskwork effort. Future research could gain additional insights into how teams cope with communication challenges by implementing conditions of high task interdependence, under which team processes are more critical (LePine et al., 2008). Yet, while more extreme conditions may bring additional insights, we showed important differences between technological conditions even in absence of strong dependencies. Second, although we manipulated CA and found more effective task-oriented communication during action, enhanced collective activity (such as more effective communication) has also been observed when other types of awareness were manipulated (although not at statistically significant levels) (Dehler et al., 2009). Future research could combine various types of awareness manipulations in one study to examine to what extent the specific types of awareness support (e.g. CA, participation awareness) affect specific types of collective activity (e.g. more effective communication, more equal participation). Third, while our paper focuses on positive consequences of SMP use, there is an increasing body of research on the negative consequences of SMP use. Researchers have argued or shown that SMP use yields cognitive overload (Freyne, Berkovsky, Daly, \& Geyer, 2010), technostress (Maier, Laumer, Weinert, \& Weitzel, 2015), and envy (Krasnova, Widjaja, Buxmann, Wenninger, \& Benbasat, 2015). These consequences may not have been very salient in our setting, where teams used the SMP to work on one project only. However, negative consequences, such as overload and technostress, may be more salient in real organizational settings where feeds show messages from many teams and individuals working on a variety of topics. Important questions are whether 
feeds are also beneficial in these conditions, how SMPs should pre-select the information to be displayed in feeds to avoid overloading individuals, and how positive and negative consequences of SMP use interact. Although these are important questions, using a relatively controlled setting in our studies was instrumental in demonstrating the potential effects of technology-enabled CA. Fourth, our paper does not focus on implementation strategies. Future research could examine structuring attempts such as collaboration scripts or real-time interventions, as scholars do in a collaboration engineering paradigm (de Vreede, Briggs, \& Massey, 2009; Massey et al., 2003). Such structuring attempts are likely to shape team processes and the resultant outcomes (Niederman et al., 2008). For instance, future work could draw on our findings on pacing and examine how scripts for temporal coordination (Massey et al., 2003) affect team communication on SMPs and the resulting outcomes. Future research could also examine how interventions described in SMP research (Laumer, Shami, Muller, \& Geyer, 2017) affect team communication.

\section{Practical Implications}

Much of the innovativeness and adaptability of contemporary organizations emanates from project teams. A key challenge for project teams is to progressively elaborate plans and ideas while new insights crystallize, work progresses, and external conditions change. Our paper shows that ICT can play an important role in this mission. Especially in settings where asynchronous multitasking prevails, project teams should consider leveraging technology-enabled communication awareness, such by collaborating over social media platforms. Social media platforms are likely to enable project teams to maintain a coherent stream of timely and steady communication after responsibilities are defined and tasks are distributed. Those teams that use the social media platform to frequently communicate may achieve superior outcomes with reduced efforts. Organizations should not only make social media platforms available to their 
project teams, they should also encourage early and frequently communication over the platform while members work on their tasks. Organizations may incorporate these recommendations in project management trainings and communication guidelines.

\section{CONCLUSION}

Teams are not collections of taskworkers; they are collectives that interact to create something that is beyond the reach of individuals (Salas et al., 1992). Our article shows that technologyenabled CA can help enable this distinctive interactive quality of teams. Results from two studies demonstrate that technology-enabled CA allows teams to benefit from team communication in episodes in which individuals devote their attention to their individual taskwork. In this sense, technology-enabled CA helps teams to leverage teams.

\section{REFERENCES}

Alge, B. J., Wiethoff, C., \& Klein, H. J. (2003). When does the medium matter? Knowledgebuilding experiences and opportunities in decision-making teams. Organizational behavior and human decision processes, 91(1), 26-37.

Andres, H. P. (2012). Technology-mediated collaboration, shared mental model and task performance. Journal of Organizational and End User Computing (JOEUC), 24(1), 6481.

Bardram, J. E., \& Hansen, T. R. (2010). Context-based workplace awareness. Computer Supported Cooperative Work (CSCW), 19(2), 105-138.

Barrick, M. R., Bradley, B. H., Kristof-Brown, A. L., \& Colbert, A. E. (2007). The moderating role of top management team interdependence: Implications for real teams and working groups. Academy of management journal, 50(3), 544-557. 
Berthon, P., Pitt, L., Ewing, M., \& Carr, C. L. (2002). Potential research space in MIS: A framework for envisioning and evaluating research replication, extension, and generation. Information Systems Research, 13(4), 416-427.

Biehl, J. T., Czerwinski, M., Smith, G., \& Robertson, G. G. (2007). FASTDash: a visual dashboard for fostering awareness in software teams. Paper presented at the Proceedings of the SIGCHI conference on Human factors in computing systems.

Bradner, E., Kellogg, W. A., \& Erickson, T. (1999). The adoption and use of 'Babble': A field study of chat in the workplace. Paper presented at the Sixth European Conference on Computer-Supported Cooperation Work '99.

Buder, J. (2007). Net-based knowledge communication in groups. Zeitschrift für Psychologie / Journal of Psychology, 215(4), 209-217.

Chiocchio, F., \& Essiembre, H. (2009). Cohesion and Performance. Small group research, 40(4), 382-420. doi:doi:10.1177/1046496409335103

Cohen, S. G., \& Bailey, D. E. (1997). What makes teams work: Group effectiveness research from the shop floor to the executive suite. Journal of management, 23(3), 239-290.

Cooper, R. B., \& Haines, R. (2008). The Influence of workspace awareness on group intellective decision effectiveness. European Journal of Information Systems, 17(6), 631-648.

Cramton, C. (2001). The mutual knowledge problem and its consequences for dispersed collaboration. Organization Science, 12(3), 346-371.

Cummings, J. N., Espinosa, J. A., \& Pickering, C. K. (2009). Crossing Spatial and Temporal Boundaries in Globally Distributed Projects: A Relational Model of Coordination Delay. Information Systems Research, 20(3), 420-439.

Dabbish, L., \& Kraut, R. E. (2008). Awareness displays and social motivation for coordinating communication. Information Systems Research, 19(2), 221-238. 
Dabbish, L., Stuart, C., Tsay, J., \& Herbsleb, J. (2012). Social coding in GitHub: transparency and collaboration in an open software repository. Paper presented at the The ACM 2012 conference on Computer Supported Cooperative Work.

Dabbish, L., Stuart, C., Tsay, J., \& Herbsleb, J. (2013). Leveraging transparency. IEEE Software, 30(1), 37-43.

De Dreu, C. K., \& West, M. A. (2001). Minority dissent and team innovation: the importance of participation in decision making. Journal of Applied Psychology, 86(6), 1191.

De Guinea, A. O., Webster, J., \& Staples, D. S. (2012). A meta-analysis of the consequences of virtualness on team functioning. Information \& Management, 49(6), 301-308.

de Vreede, G. J., Briggs, R. O., \& Massey, A. P. (2009). Collaboration engineering: foundations and opportunities: editorial to the special issue on the journal of the association of information systems. Journal of the Association for Information Systems, 10(3), 7.

Dehler, J., Bodemer, D., Buder, J., \& Hesse, F. W. (2009). Providing group knowledge awareness in computer-supported collaborative learning: Insights into learning mechanisms. Research and Practice in Technology Enhanced Learning, 4(2), 111-132.

Dennis, A. R., Wixom, B. H., \& Vandenberg, R. J. (2001). Understanding fit and appropriation effects in group support systems via meta-analysis. MIS Quarterly, 25(2), 167-193.

DeSanctis, G., Poole, M. S., Zigurs, I., DeSharnais, G., D'Onofrio, M., Gallupe, B., . . Lewis, H. (2008). The Minnesota GDSS Research Project: Group support systems, group processes, and outcomes. Journal of the Association for Information Systems, 9(10/11), 551.

Dourish, P., \& Bellotti, V. (1992). Awareness and coordination in shared workspaces. Paper presented at the ACM Conference on Computer-Supported Cooperative Work, Toronto, Ontario, Canada.

Endsley, M. R. (1995). Toward a theory of situation awareness in dynamic systems. Human Factors: The Journal of the Human Factors and Ergonomics Society, 37(1), 32-64. 
Erickson, T., \& Kellogg, W. A. (2000). Social translucence: an approach to designing systems that support social processes. ACM Transactions on Computer-Human Interaction (TOCHI), 7(1), 59-83.

Espinosa, J. A., Cadiz, J., Rico-Gutierrez, L., Kraut, R. E., Scherlis, W., \& Lautenbacher, G. (2000). Coming to the wrong decision quickly: why awareness tools must be matched with appropriate tasks. Paper presented at the SIGCHI Conference on Human Factors in Computing Systems, The Hague, Netherlands.

Espinosa, J. A., Cummings, J. N., \& Pickering, C. (2012). Time separation, coordination, and performance in technical teams. IEEE Transactions on Engineering Management, 59(1), 91-103.

Espinosa, J. A., Nan, N., \& Carmel, E. (2015). Temporal distance, communication patterns, and task performance in teams. Journal of Management Information Systems, 32(1), $151-191$

Freyne, J., Berkovsky, S., Daly, E. M., \& Geyer, W. (2010). Social networking feeds: recommending items of interest. Paper presented at the Proceedings of the fourth ACM conference on Recommender systems.

Fussell, S. R., Kraut, R. E., Lerch, F. J., Scherlis, W. L., McNally, M. M., \& Cadiz, J. J. (1998). Coordination, overload and team performance: effects of team communication strategies. Paper presented at the ACM Conference on Computer Supported Cooperative Work, Seattle, WA, USA.

Galegher, J., \& Kraut, R. E. (1994). Computer-mediated communication for intellectual teamwork: An experiment in group writing. Information Systems Research, 5(2), 110138.

Gersick, C. J. (1988). Time and transition in work teams: Toward a new model of group development. Academy of management journal, 31(1), 9-41. 
Gersick, C. J. (1989). Marking time: Predictable transitions in task groups. Academy of management journal, 32(2), 274-309.

Gopal, A., \& Gosain, S. (2010). The role of organizational controls and boundary spanning in software development outsourcing: Implications for project performance. Information Systems Research, 21(4), 1-23.

Gutwin, C., \& Greenberg, S. (2002). A descriptive framework of workspace awareness for realtime groupware. Computer Supported Cooperative Work (CSCW), 11(3-4), 411-446.

Gutwin, C., Greenberg, S., \& Roseman, M. (1996). Workspace awareness in real-time distributed groupware: Framework, widgets, and evaluation. In M. A. Sasse, R. J. Cunningham, \& R. L. Winder (Eds.), People and computers XI: Proceedings of HCl'96 (pp. 281-298). London: Springer London.

Gutwin, C., Penner, R., \& Schneider, K. (2004). Group awareness in distributed software development. Paper presented at the ACM Conference on Computer Supported Cooperative Work, Chicago, Illinois, USA.

He, J., Butler, B. S., \& King, W. R. (2007). Team cognition: Development and evolution in software project teams. Journal of Management Information Systems, 24(2), 261-292.

Heath, C., Svensson, M. S., Hindmarsh, J., Luff, P., \& vom Lehn, D. (2002). Configuring awareness. Computer Supported Cooperative Work (CSCW), 11(3), 317-347.

Hinds, P. J., \& Bailey, D. E. (2003). Out of sight, out of sync: Understanding conflict in distributed teams. Organization Science, 16(3), 615-632.

Hoegl, M., \& Parboteeah, P. (2006). Autonomy and teamwork in innovative projects. Human Resource Management, 45(1), 67-79.

Humphrey, S. E., \& Aime, F. (2014). Team microdynamics: Toward an organizing approach to teamwork. The academy of management annals, 8(1), 443-503. 
Ilgen, D. R., Hollenbeck, J. R., Johnson, M., \& Jundt, D. (2005). Teams in organizations: From input-process-output models to IMOI models. Annual review of psychology, 56(1), 517543.

Janssen, J., Erkens, G., \& Kirschner, P. A. (2011). Group awareness tools: It's what you do with it that matters. Computers in human behavior, 27(3), 1046-1058.

Kanawattanachai, P., \& Yoo, Y. (2007). The impact of knowledge coordination on virtual team performance over time. MIS Quarterly, 31(4), 783-808.

Keller, R. T. (1994). Technology-information processing fit and the performance of R\&D project groups: A test of contingency theory. Academy of management journal, 37(1), 167-179.

Kimmerle, J., \& Cress, U. (2008). Group awareness and self-presentation in computersupported information exchange. International Journal of Computer-Supported Collaborative Learning, 3(1), 85-97.

Kock, N., \& Lynn, G. S. (2012). Research Article Electronic Media Variety and Virtual Team Performance: The Mediating Role of Task Complexity Coping Mechanisms. IEEE Transactions on Professional Communication, 55(4), 325-344.

Krasnova, H., Widjaja, T., Buxmann, P., Wenninger, H., \& Benbasat, I. (2015). Research notewhy following friends can hurt you: an exploratory investigation of the effects of envy on social networking sites among college-age users. Information Systems Research, 26(3), 585-605.

Krippendorff, K. (2012). Content analysis: An introduction to its methodology. Thousand Oaks, CA: Sage.

Landis, J. R., \& Koch, G. G. (1977). The measurement of observer agreement for categorical data. Biometrics, 33(1), 159-174.

Laumer, S., Shami, N. S., Muller, M., \& Geyer, W. (2017). The Challenge of Enterprise Social Networking (Non-) Use at Work: A Case Study of How to Positively Influence Employees' Enterprise Social Networking Acceptanc. Paper presented at the 
Proceedings of the 2017 ACM Conference on Computer Supported Cooperative Work and Social Computing.

Law, J. (2016). Effiency. Dictionary of Business and Management. Retrieved from http://www.oxfordreference.com/view/10.1093/oi/authority.20110803095743578

Leonardi, P. M. (2014). Social media, knowledge sharing, and innovation: Toward a theory of communication visibility. Information Systems Research, 25(4), 796-816.

Leonardi, P. M. (2015). Ambient awareness and knolwedge acquisition: Using social media to learn "Who Knows What" and "Who Knows Whom". MIS Quarterly, 39(4), 747-762.

Leonardi, P. M., Huysman, M., \& Steinfield, C. (2013). Enterprise social media: Definition, history, and prospects for the study of social technologies in organizations. Journal of Computer-Mediated Communication, 19(1), 1-19.

LePine, J. A., Piccolo, R. F., Jackson, C. L., Mathieu, J. E., \& Saul, J. R. (2008). A metaanalysis of teamwork processes: tests of a multidimensional model and relationships with team effectiveness criteria. Personnel psychology, 61(2), 273-307.

Lowry, P. B., \& Nunamaker, J. F., Jr. (2003). Using Internet-based, distributed collaborative writing tools to improve coordination and group awareness in writing teams. Professional Communication, IEEE Transactions on, 46(4), 277-297. doi:10.1109/TPC.2003.819640

Ma, M., \& Agarwal, R. (2007). Through a glass darkly: Information technology design, identity verification, and knowledge contribution in online communities. Information Systems Research, 18(1), 42-67.

Maier, C., Laumer, S., Weinert, C., \& Weitzel, T. (2015). The effects of technostress and switching stress on discontinued use of social networking services: a study of Facebook use. Information Systems Journal, 25(3), 275-308. 
Malhotra, A., \& Majchrzak, A. (2014). Enhancing performance of geographically distributed teams through targeted use of information and communication technologies. Human Relations, 67(4), 389-411. doi:10.1177/0018726713495284

MarketsandMarkets. (2017). Enterprise Collaboration Market worth 49.51 Billion USD by 2021. Retrieved from http://www.marketsandmarkets.com/PressReleases/enterprisecollaboration.asp

Markopoulos, P., \& Mackay, W. (2009). Awareness systems: Advances in theory, methodology and design. Heidelberg, Germany: Springer.

Marks, M. A., Mathieu, J. E., \& Zaccaro, S. J. (2001). A temporally based framework and taxonomy of team processes. Academy of management review, 26(3), 356-376.

Maruping, L. M., Venkatesh, V., Thatcher, S. M. B., \& Patel, P. C. (2015). Folding under pressure or rising to the occasion? Perceived time pressure and the moderating role of team temporal leadership. Academy of management journal, 58(5), 1313-1333.

Massey, A. P., Montoya-Weiss, M. M., \& Hung, Y.-T. (2003). Because time matters: Temporal coordination in global virtual project teams. Journal of Management Information Systems, 19(4), 129-156.

Mathieu, J. E., Maynard, M. T., Rapp, T., \& Gilson, L. (2008). Team effectiveness 1997-2007: A review of recent advancements and a glimpse into the future. Journal of management, 34(3), 410-476.

Mathieu, J. E., \& Schulze, W. (2006). The Influence of Team Knowledge and Formal Plans on Episodic Team Process-Performance Relationships. Academy of management journal, 49(3), 605-619. doi:10.5465/amj.2006.21794678

McGrath, J. E. (1991). Time, interaction, and performance (TIP): A theory of groups. Small group research, 22(2), 147-174. 
McGrath, J. E., Arrow, H., Gruenfeld, D. H., Hollingshead, A. B., \& O'Connor, K. M. (1993). Groups, tasks, and technology: The effects of experience and change. Small group research, 24(3), 406-420.

Mintzberg, H., Raisinghani, D., \& Théorêt, A. (1976). The structure of "Unstructured" decision processes. Administrative Science Quarterly, 21(2), 246-275.

Niederman, F., Briggs, R. O., de Vreede, G.-J., \& Kolfschoten, G. L. (2008). Extending the Contextual and Organizational Elements of Adaptive Structuration Theory in GSS Research. Journal of the Association for Information Systems, 9(10/11), 633-652.

Ocker, R., Hiltz, S. R., Turoff, M., \& Fjermestad, J. (1995). The effects of distributed group support and process structuring on software requirements development teams: Results on creativity and quality. Journal of Management Information Systems, 12(3), 127-153.

Okhuysen, G. A., \& Eisenhardt, K. M. (2002). Integrating knowledge in groups: How formal interventions enable flexibility. Organization Science, 13(4), 370-386.

Omoronyia, I., Ferguson, J., Roper, M., \& Wood, M. (2009). Using developer activity data to enhance awareness during collaborative software development. Computer Supported Cooperative Work (CSCW), 18(5-6), 509.

Paas, F., Tuovinen, J. E., Tabbers, H., \& Van Gerven, P. W. M. (2003). Cognitive load measurement as a means to advance cognitive load theory. Educational psychologist, 38(1), 63-71.

Pearsall, M. J., Ellis, A. P., \& Bell, B. S. (2010). Building the infrastructure: the effects of role identification behaviors on team cognition development and performance. Journal of Applied Psychology, 95(1), 192.

Pridmore, J., \& Phillips-Wren, G. (2011). Assessing decision making quality in face-to-face teams versus virtual teams in a virtual world. Joumal of Decision Systems, 20(3), 283308. 
Salas, E., Dickinson, T. L., Converse, S. A., \& Tannenbaum, S. I. (1992). Toward an understanding of team performance and training. In R. W. S. E. Salas (Ed.), Teams: Their training and performance (pp. 3-29). Westport, CT, US: Ablex Publishing.

Salas, E., Sims, D. E., \& Burke, C. S. (2005). Is there a "Big Five" in teamwork? Small group research, 36(5), 555-599.

Sangin, M., Molinari, G., Nüssli, M.-A., \& Dillenbourg, P. (2011). Facilitating peer knowledge modeling: Effects of a knowledge awareness tool on collaborative learning outcomes and processes. Computers in human behavior, 27(3), 1059-1067.

Schmidt, K. (2002). The problem with 'Awareness': Introductory remarks on 'Awareness in CSCW'. Computer Supported Cooperative Work (CSCW), 11(3), 285-298.

Schweitzer, L., \& Duxbury, L. (2010). Conceptualizing and measuring the virtuality of teams. Information Systems Journal, 20(3), 267-295.

Tran, M. H., Yang, Y., \& Raikundalia, G. K. (2009). Conversational Awareness in Text-Based Computer Mediated Communication. In P. Markopoulos, B. De Ruyter, \& W. Mackay (Eds.), Awareness Systems: Advances in Theory, Methodology and Design (pp. 313333). London: Springer London.

Treude, C., \& Storey, M.-A. (2010). Awareness 2.0: staying aware of projects, developers and tasks using dashboards and feeds. Paper presented at the Proceedings of the 32nd ACM/IEEE International Conference on Software Engineering-Volume 1.

Venkatesh, V., Morris, M. G., Davis, G. B., \& Davis, F. D. (2003). User acceptance of information technology: Toward a unified view. MIS Quarterly, 425-478.

Waller, M. J., Conte, J. M., Gibson, C. B., \& Carpenter, M. A. (2001). The effect of individual perceptions of deadlines on team performance. Academy of management review, 26(4), 586-600. 
Waller, M. J., Zellmer-Bruhn, M. E., \& Giambatista, R. C. (2002). Watching the clock: Group pacing behavior under dynamic deadlines. Academy of management journal, 45(5), 1046-1055.

Weisband, S. P. (2002). Maintaining awareness in distributed team collaboration: Implications for leadership and performance. In P. J. Hinds \& S. Kiesler (Eds.), Distributed work (pp. 235-257). Cambridge, MA: MIT Press.

Wooldridge, J. M. (2009). Introductory Econometrics - a Modern Approach (4th ed.). Mason, $\mathrm{OH}$ : South-Western Cengage Learning.

Yang, X., Tong, Y., \& Teo, H. H. (2015). Fostering Fast-response Spontaneous Virtual Team: Effects of Member Skill Awareness and Shared Governance on Team Cohesion and Outcomes. Journal of the Association for Information Systems, 16(11), 919.

Zhang, X., Venkatesh, V., \& Brown, S. A. (2011). Designing collaborative systems to enhance team performance. Journal of the Association for Information Systems, 12(8), 556-585. 


\section{APPENDIX A: SCREENSHOTS}

\section{Low-Communication Awareness Condition}

The following figures illustrate the user interface and capabilities of the platform in the low-CA condition. The figures show mock-ups that we created with a design tool. We used mock-ups to improve the readability of the screenshots, to translate text into English, and to protect the privacy of the study participants. The figures are schematic, but accurate representations of the actual tool. They include actual communication that has been translated into English. The names of the participants are pseudonyms.

Figure 5 shows the team page. Call-outs show how users could trigger tool capabilities by clicking on elements of the team page. These capabilities include:

(1) Communicating by (1a) clicking the envelope to view or send direct message (see Figure 6), by (1b) clicking forum topic to view or make forum posts (see Figure 7), and by (1c) viewing or updating user profiles (see Figure 8)

(2) Relationship building by viewing and modifying friend relationships (see Figure 8)

(3) Concurrent artifact editing by clicking artifacts (such as "Answer document") in order to be redirected to Google Docs 


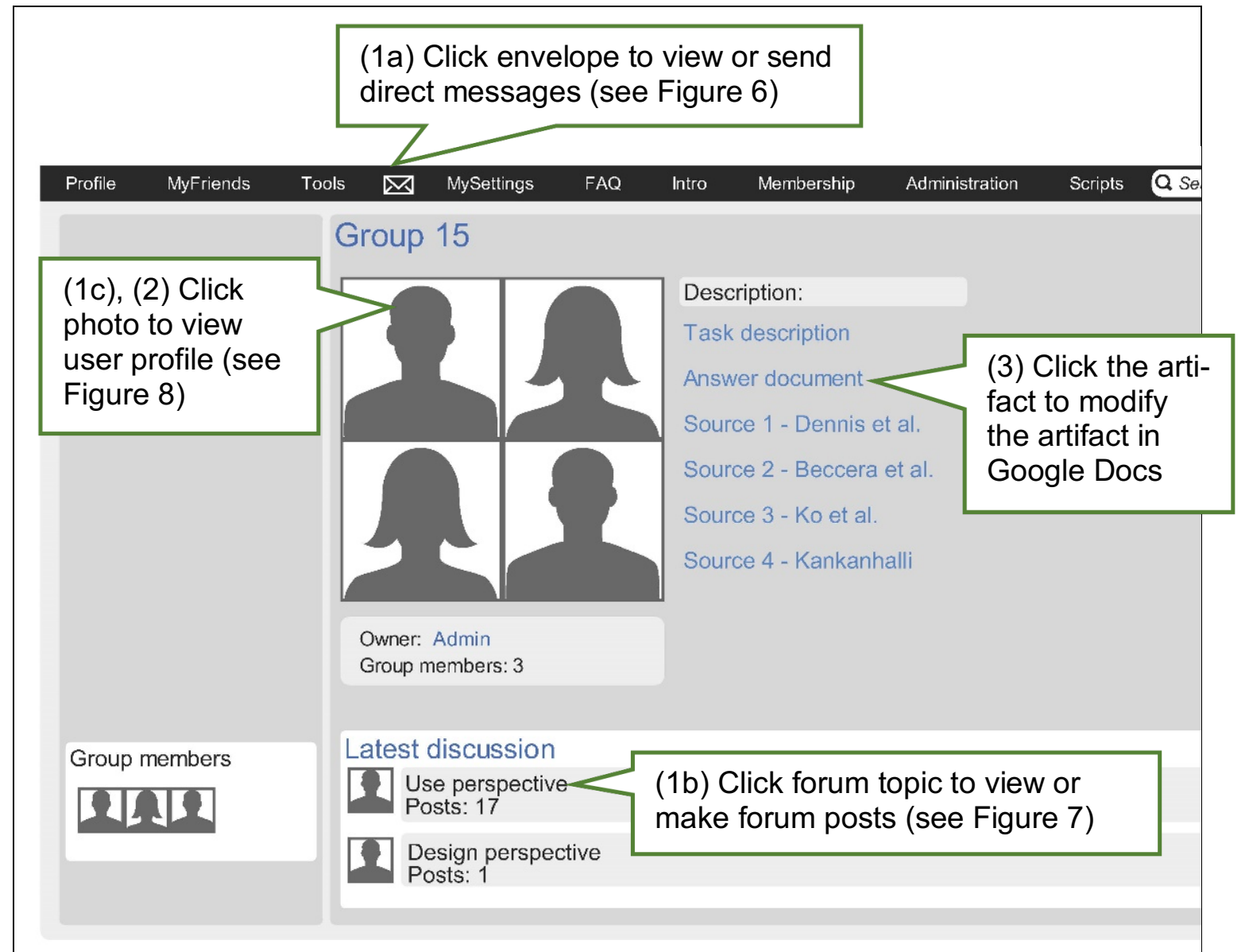

Figure 5. Team Page (Low-CA Condition)

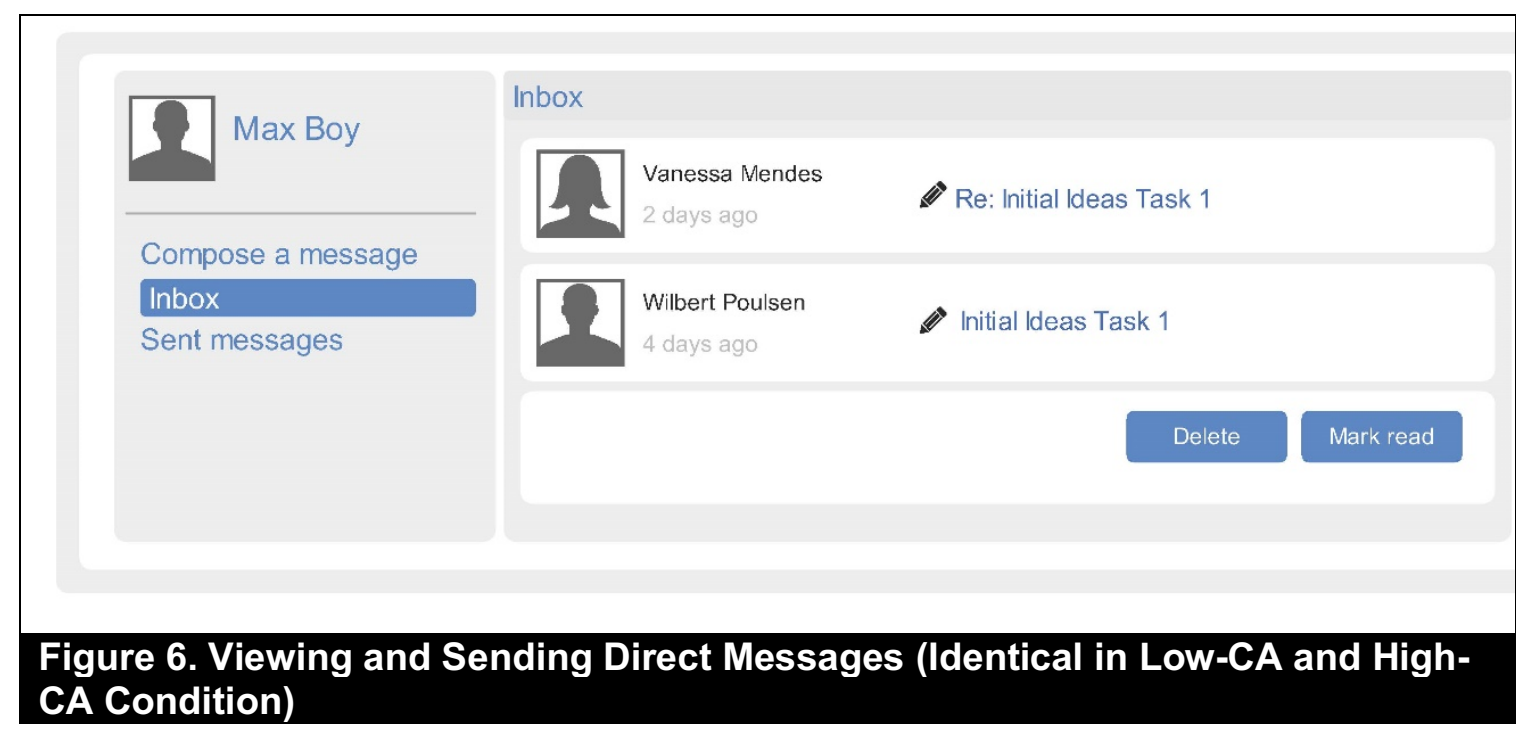


Use Perspective

$5 . \begin{aligned} & \text { Svenja Ruge } \\ & 3 \text { days }\end{aligned}$

Hi Girls!

I'm Svenja, and I guess we are going to do the group work together.

How are we going to do it?

Svenja

Delete Edit

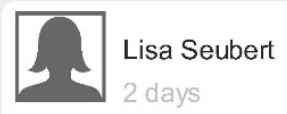

Hi you,

Im not sure how to submit the group work - I connot find any information...?

I'm planing to work on it in the end of this week and next week.

I haven't done anything yet.

Do you want to meet? I don't really have a lot of time. I could do Monday morning or

Thursday afternoon. Maybe it's possible to do the whole thing online.

Greetinas.

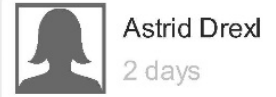

Hi everyone!

I'm working a lot and I'm not that often at university. I'm free on Wednesday and

Thursday afternoon.

It makes no difference to me how we organize it.... Anyway I think it could work out online.

I guess we have to submit it on 17/18 of May.

Cheers,

Astrid

Post a comment

Figure 7. Viewing and Making Forum Posts (Identical in Low-CA and High-CA Condition) 


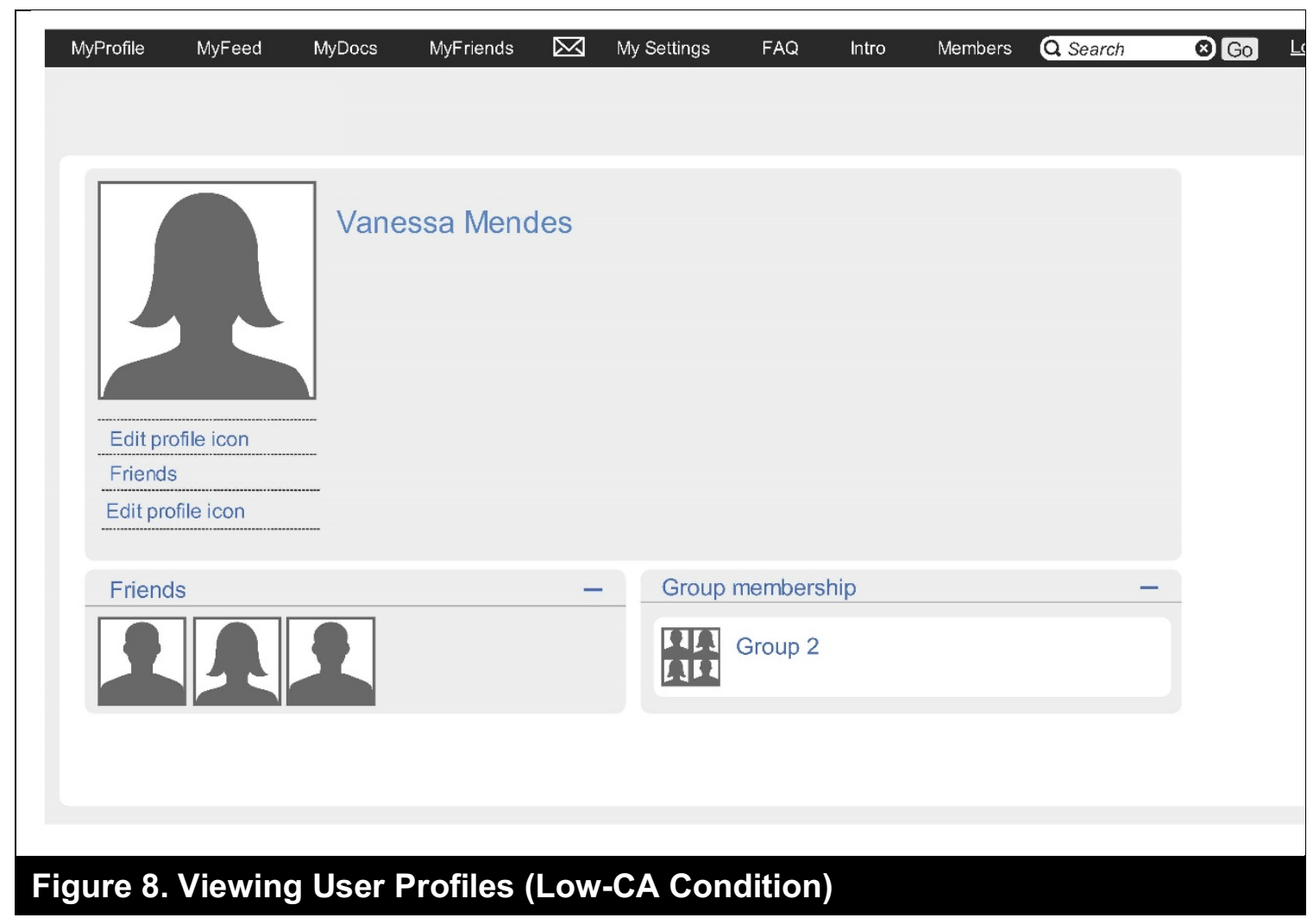

\section{High-CA Condition}

The following figures illustrate the user interface and capabilities of the enhanced platform. Figure 9 shows the team page of the enhanced platform. Call-outs show how users could trigger tool capabilities by clicking on elements of the team page. These capabilities include all capabilities of the basic platform and the following:

(4) Communication awareness: Viewing all communication at one place by (4a) clicking "MyFeed" to view the team feed (see Figure 10) or by (4b) viewing the user profile page, which included an individual feed (see Figure 11). 


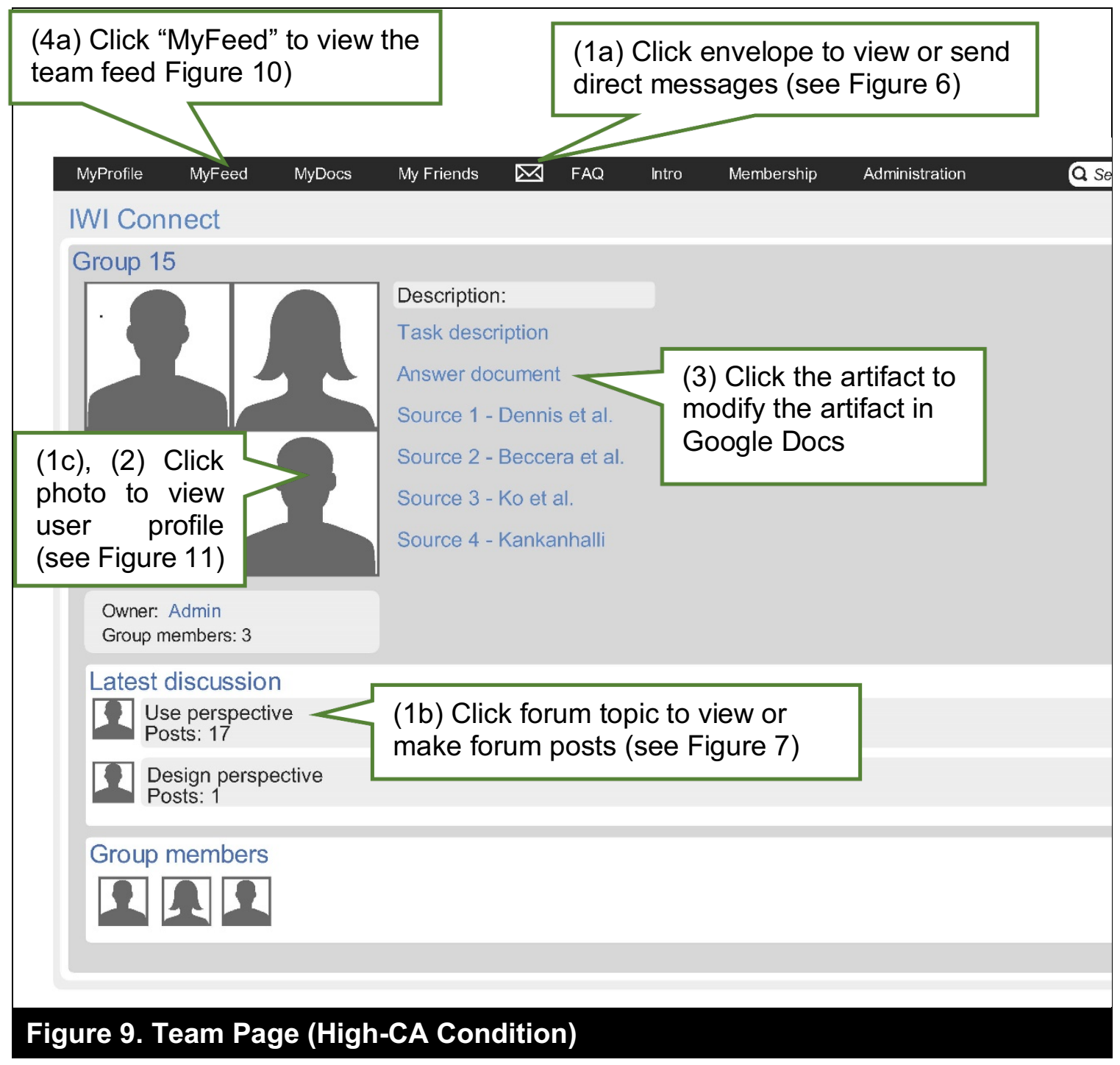




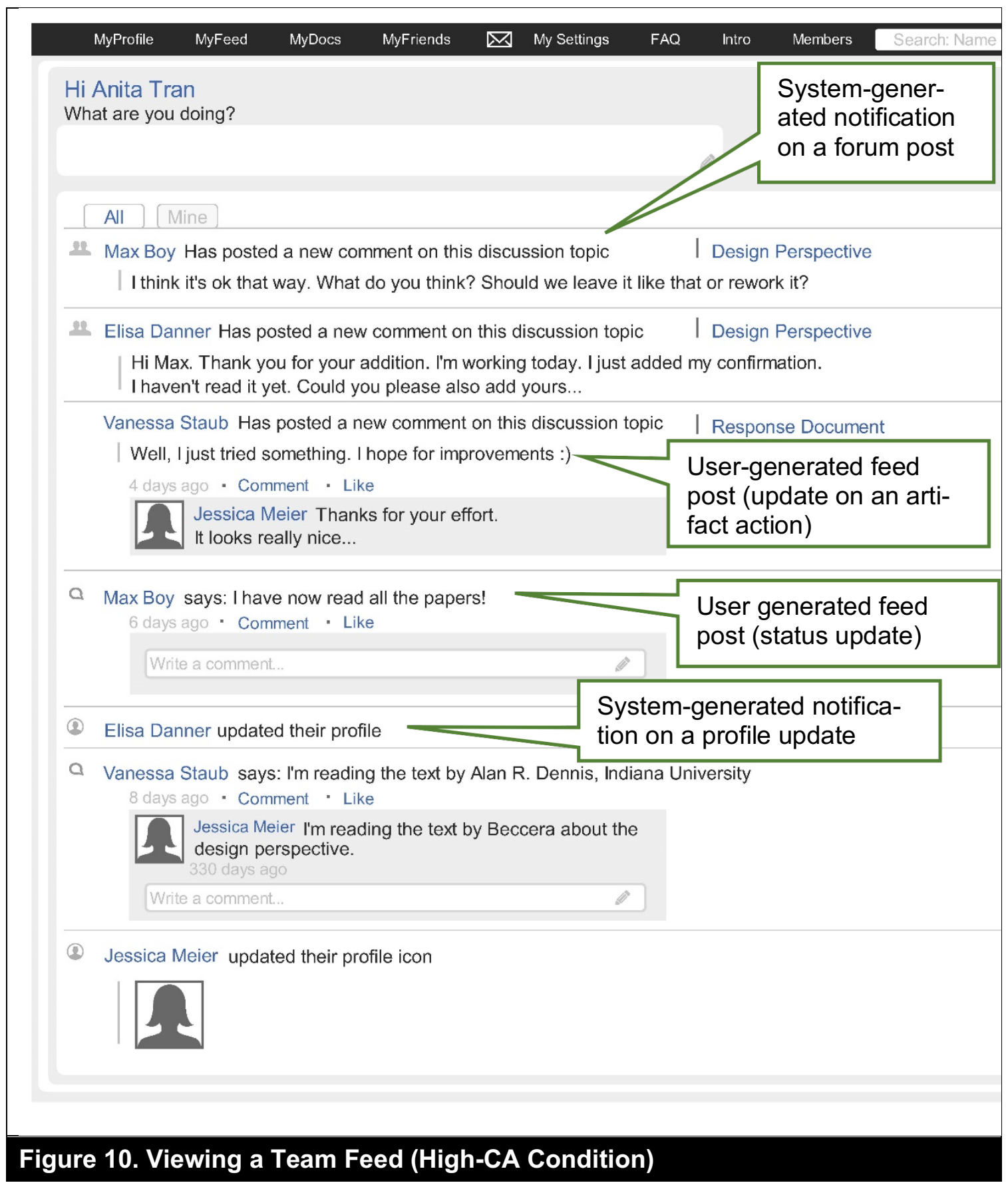




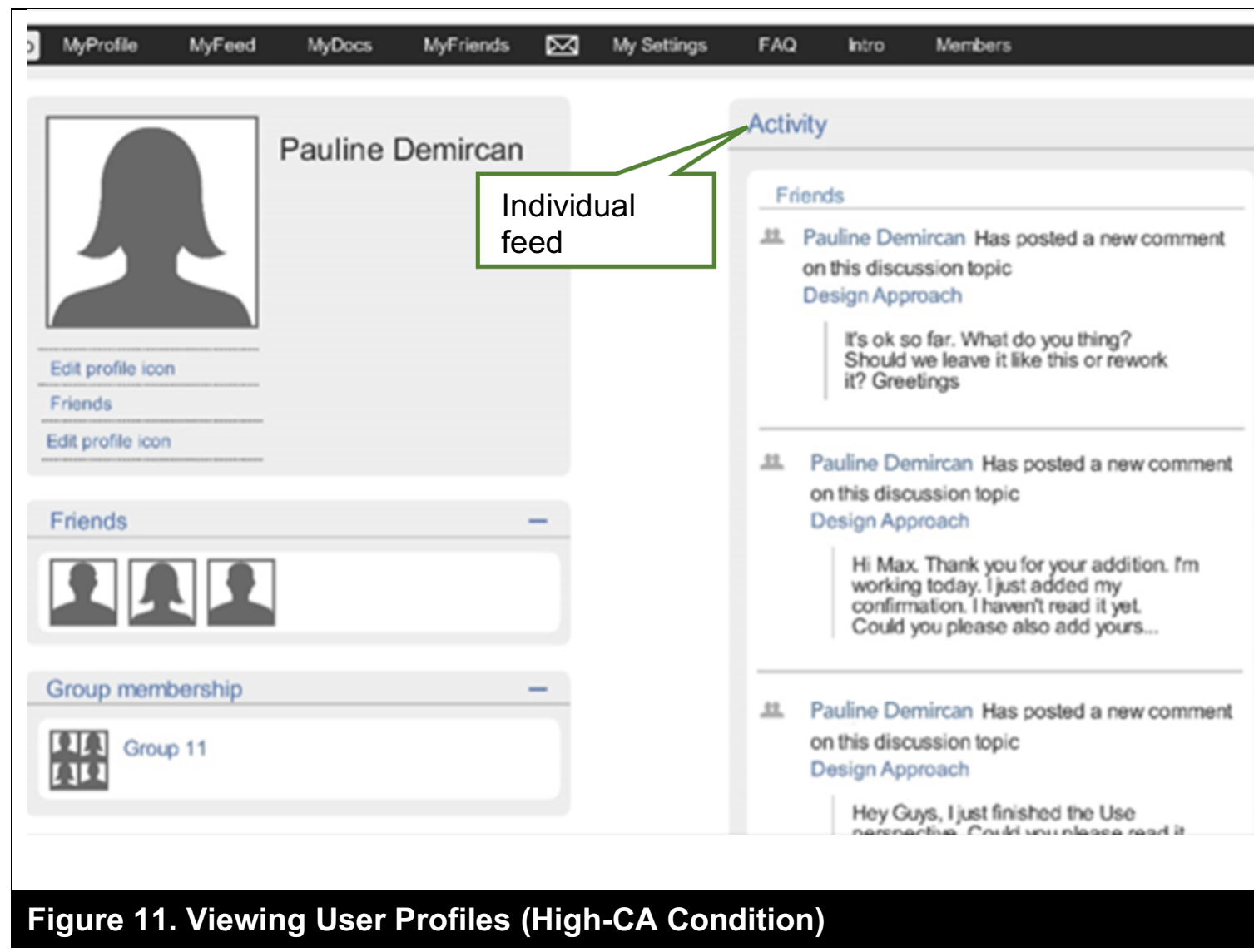

\section{APPENDIX B: TASK MATERIAL OF STUDY 1}

The following text is a translated and shortened summary of the task material of study 1 .

Process improvement is a top priority of the XYZ bank. The board asked the managers of the local subsidiaries to make suggestions for process improvement to the board. The board also asked a consultancy to analyze the processes. The task of the consultants is to identify potential for process improvement in the two local subsidiaries $A$ and $B$.

You are a member of the team of consultants. Please familiarize with the information provided on the credit request approval process in the attached documents. Work on the following tasks related to the credit request approval process: 
(1) Map the credit request approval process for subsidiaries A and B using an appropriate process mapping technique. The process model should include information on time and resources.

(2a) How can subsidiary A reduce the cycle time of the credit request approval process?

(2b) What type and amount of costs can subsidiary A save if they follow your suggestions?

(2c) If the bank decided to delegate the process step credit check of the credit request approval process to a shared service center, how will the process model, cycle times, and costs change?

(2d) If a new groupware allowed the bank to simultaneously perform credit check and property check, who would that affect the credit approval process mapped in task 1?

The following tasks refer to the bank $\mathrm{XYZ}$ as a whole rather than to the process approval process only. Please familiarize with the attached document that shows the results of a process analysis of the $\mathrm{XYZ}$ bank conducted by the consultancy company.

(3a) Please compare cycle times, salary classes, and costs across subsidiaries.

(3b) What should XYZ do improve cycle times and costs?

(3c) What type and amount of costs can the $X Y Z$ save if they follow your suggestions?

(3d) What context factors should the bank account for when they implement the suggested actions?

(4) The bank considers outsourcing the credit request approval process to service provider SP. Please provide a recommendation for whether and how the bank should outsource particular steps of the credit request approval process. 


\section{APPENDIX C: TASK MATERIAL OF STUDY 2}

You are member of a team at a consultancy for knowledge management systems. Sebastian Kalinke, head of the department "Nuclear Safeguards" at the International Nuclear Energy Agency (INEA) approached you for help. After the Fokushima disaster, the United Nations asked Kalinke's department to develop safety standards for different types of nuclear reactors and to communicate these specifications to the power plant operators.

Defining nuclear safety standards is a highly complex task. A number of risk factors need to be identified, analyzed, and evaluated to define appropriate measures. Kalinke's department employs several risk experts. Risk experts are intimately familiar with mathematical approaches for calculating risks. Yet, insight from the Fokushima disaster suggests that these calculations were based on unrealistic assumptions. To improve the specification of the risk estimation models, risk experts need to collaborate with experts in nuclear physics. Moreover, Kalinke's team needs to collaborate with external actors, such as the electric engineers working in the businesses responsible for the cooling equipment for nuclear power plants. Finally, construction engineers need to be involved to provide knowledge on possible constructional changes in the power plants. Kalinke has been asked to balance the safety gains from additional measures with the profit interests of power plant operators. Please familiarize with the information provided in the attached documents.

a) Suggest a knowledge management system that helps Kalinke's team develop safety standards. Base your suggestions on an article by Dennis \& Vessey or on an article by Becerra-Ferndandez \& Sabherwal or on both.

b) Suggest specific actions to ensure that employees make beneficial use of the knowledge management system. 


\section{APPENDIX D: CODING EXAMPLES}

Table 12 provides examples for the coding of task-oriented communication. A message was coded as task-oriented if it referred to the process or the substance of the task. The last column provides a brief rationale for each coding decision. The messages are taken from different teams.

\begin{tabular}{|c|c|c|}
\hline Message & $\begin{array}{l}\text { Code: } \\
\text { Task-Ori- } \\
\text { ented }\end{array}$ & Coding Rationale \\
\hline $\begin{array}{l}\text { Hello hello how should we go about the task? Should every- } \\
\text { one do everything and we define until when this should be } \\
\text { done? Or should everyone simply take over one task (which } \\
\text { is a bit difficult because of the different effort)? Kind regards }\end{array}$ & Yes & $\begin{array}{l}\text { Process (how the team will } \\
\text { go about organizing the work } \\
\text { on the task) }\end{array}$ \\
\hline $\begin{array}{l}\text { I will finish task } 2 \text { over the weekend. I have not yet had time } \\
\text { to do that } \ldots=/\end{array}$ & Yes & $\begin{array}{l}\text { Process (what the sender } \\
\text { has done so far and what } \\
\text { the sender is planning to do } \\
\text { next) }\end{array}$ \\
\hline $\begin{array}{l}\text { Hi Marc, I basically like your process model. There are two } \\
\text { possibilities for modelling delays [in Petrinets]: } 1 \text { ) You put the } \\
\text { delay next to the place, then it is interpreted as idle time, i.e. } \\
\text { the team that a tokan has to wait in a place until the token } \\
\text { can move to the next place or 2) you put the delay next to the } \\
\text { transition, then it is interpreted as transition time, i.e. time un- } \\
\text { til the token arrives at the next place. Since the firing of tran- } \\
\text { sitions does not take time, the two options mean the same } \\
\text { thing. Perhaps you may want to put the delays next to the } \\
\text { places, then everything is fine. Kind regards }\end{array}$ & Yes & $\begin{array}{l}\text { Substance (how delays are } \\
\text { incorporated into Petrinets) }\end{array}$ \\
\hline $\begin{array}{l}\text { Does anyone of you know what I shall do with the different } \\
\text { salary levels? }\end{array}$ & Yes & $\begin{array}{l}\text { Substance (the sender is } \\
\text { asking a question related to } \\
\text { the content of the task) }\end{array}$ \\
\hline $\begin{array}{l}\text { I am finished with task 2. Please tell me if anything looks } \\
\text { strange. What I noted on task 1: Should we perhaps divide } \\
\text { the credit check into "if creditworthiness is ok" and "if credit- } \\
\text { worthiness is not ok" (and the credit request is rejected)? } \\
\text { What do you think? }\end{array}$ & Yes & $\begin{array}{l}\text { Process (what the sender } \\
\text { has done) and substance } \\
\text { (feedback on task 1) }\end{array}$ \\
\hline All the best for the exams to everyone!! & No & \multirow{5}{*}{$\begin{array}{l}\text { Neither substance nor pro- } \\
\text { cess }\end{array}$} \\
\hline Hello ;-) & No & \\
\hline This is going to be real fun ;-) haha & No & \\
\hline Do you all understand Swiss German? & No & \\
\hline $\begin{array}{l}\text { This [artifact editor] is really a pain. I would be faster if I had } \\
\text { to carve everything in stone. }\end{array}$ & No & \\
\hline
\end{tabular}


Table 13 illustrates the coding of episodes. The table shows the first 15 messages of one team. Through the messages 1 to 13 , the team defined how they planned to accomplish the task. Message 13 on day 4 ("Right, Peter :-), let's do it like this") was the last message that was coded as initial strategy formulation. Hence, day 4 was coded as the last day of initial strategy formulation of this team. Consequently, all messages that this team sent after day 4 (i.e., all messages from \#14 onwards) were considered to belong to action episodes.

\begin{tabular}{|c|c|c|c|}
\hline \# & Sender & Message & Day \\
\hline 1 & Max & Hi, how should we go about this work? & 2 \\
\hline 2 & Jenny & Good question ... how should we divide the tasks? & 3 \\
\hline 3 & Max & First, it would be nice if everyone could post a message here. & 3 \\
\hline 4 & Peter & $\begin{array}{l}\text { Hi. I just found my way into [the collaboration platform]. I like process } \\
\text { mapping, but I guess this is the post popular part of this work. So I am } \\
\text { happy to submit myself to the group. Do you have any preferences? }\end{array}$ & 3 \\
\hline 5 & Jenny & $\begin{array}{l}\text { I do not absolutely have to do process mapping ;-) So, Peter, it is ok for } \\
\text { me if you do that part of the work. }\end{array}$ & 3 \\
\hline 6 & Laurent & $\begin{array}{l}\text { Hi everyone. Sorry for my late reply. Let me propose the following division } \\
\text { of work (under the assumption that the distribution of points per tasks cor- } \\
\text { relates with effort): If Peter does the process mapping, he will do task } 1 \\
(15 \%) \text {. I would like to do task } 2 \text { and task } 4(25 \%) \text {. Thus, I would do } 25 \% \text {. I } \\
\text { prefer this because I would then work on my own. .. Then Jenny and Max } \\
\text { could do Task } 3 \text {. With this division of tasks, Peter would do } 15 \% \text {, Jenny } \\
\text { and Max } 30 \% \text { and I } 25 \% \text {. Peter could help Jenny and Max on task } 3 \text { to } \\
\text { make everything fairer. What do you think? :-) }\end{array}$ & 4 \\
\hline 7 & Peter & $\begin{array}{l}\text { Hi Laurent. Thank you for this very concrete post. I am fine with it but I } \\
\text { would wait for Max' and Jenny's answer. I am happy to help on task } 3 \text {. Fi- } \\
\text { nally, that's what [the collaboration platform] is for. :-) }\end{array}$ & 4 \\
\hline 8 & Max & $\begin{array}{l}\text { I am also fine with the suggestion. Since Peter would have only } 15 \% \text { of } \\
\text { the work. He could also work on task } 4 \text { and he would have } 25 \% \text {. Provided } \\
\text { that Peter and Jenny are fine with this. }\end{array}$ & 4 \\
\hline 9 & Jenny & Ok, I am fine with this suggestion & 4 \\
\hline 10 & Peter & $\begin{array}{l}\text { I think it is not important whether I do task } 4 \text { and Laurent has } 15 \% \text { or vice- } \\
\text { versa, I just propose that whoever has only } 15 \% \text { should provide help on } \\
\text { task } 3 \text { on demand. I would also be happy with doing task } 4 \text {. Laurent, what } \\
\text { would you prefer? }\end{array}$ & 4 \\
\hline 11 & Max & $\begin{array}{l}\text { Sorry, I had not read your messages well, my fault ;-). Yes, ok, Peter, you } \\
\text { would help on task } 3 \text {, that's ok. Sorry ;-) }\end{array}$ & 4 \\
\hline
\end{tabular}




\begin{tabular}{|l|l|l|l|}
\hline 12 & Peter & $\begin{array}{l}\text { No problem ;-) I think we now have agreed on a way to proceed. Laurent } \\
\text { had made the proposal, so for sure he will also agree. Since I am cur- } \\
\text { rently in the mid of the work on a seminar thesis, I will have time to start } \\
\text { the process mapping task only next week. Is there anyone who depends } \\
\text { on task 1 (process mapping)? }\end{array}$ & 4 \\
\hline 13 & Laurent & $\begin{array}{l}\text { Right, Peter :-), let's do it like this. My task 2 is quite strongly dependent } \\
\text { on your process mapping task. I plan to work on my task next week on } \\
\text { Thursday and Friday. On Thursday I will only revise the theory. So it } \\
\text { would be great if you could finish your process mapping until Friday. } \\
\text { Would you be fine with this, Peter? If this timeline is too tight, we would } \\
\text { find another way. }\end{array}$ & 4 \\
\hline 14 & Peter & $\begin{array}{l}\text { Please do not move any [Petrinet] symbols, please only copy them. Task } \\
\text { 1 is more effortful than expected! I will try to finish it by tomorrow. Kind re- } \\
\text { gards, Peter }\end{array}$ & 9 \\
\hline 15 & Peter & $\begin{array}{l}\text { @Laurent: I finished the process mapping task ... Some things are not } \\
\text { yet complete. I will check that based on the theory, if possible until Sun- } \\
\text { day. But I think that you can start working with the current version of the } \\
\text { process model. The model includes all relevant information. By the way, I } \\
\text { tried to avoid mistakes, but there may still be some. Please write me if } \\
\text { you note any issues. I think it is not ideal if anyone did just directly modify } \\
\text { the process model. Please write me and I change the model. }\end{array}$ & 11 \\
\hline ... & \begin{tabular}{l} 
\\
\hline
\end{tabular}
\end{tabular}

\section{APPENDIX E: SURVEY ITEMS FOR OFFLINE COMMUNICATION}

(1) I often communicated with my team members outside of the environment (e.g., via phone, email, personal meetings)

(2) Our team met multiple times.

(3) I often had offline contact with my team members. 
APPENDIX F: PACING OF TASK-ORIENTED COMMUNICATION FOR

DIFFERENT LEVELS OF EFFICIENCY

\begin{tabular}{|c|c|c|c|c|c|c|}
\hline \multirow[b]{2}{*}{ Indicator } & \multicolumn{3}{|c|}{$\begin{array}{l}\text { Low-Performing } \\
\text { (Low Efficiency) }\end{array}$} & \multicolumn{3}{|c|}{$\begin{array}{l}\text { High-Performing } \\
\text { (High Efficiency) }\end{array}$} \\
\hline & $\begin{array}{c}\text { Low } \\
\text { CA }\end{array}$ & $\begin{array}{c}\text { High } \\
\text { CA }\end{array}$ & $\Delta$ & $\begin{array}{c}\text { Low } \\
\text { CA }\end{array}$ & $\begin{array}{c}\text { High } \\
\text { CA }\end{array}$ & $\Delta$ \\
\hline Study 1 & $n=17$ & $n=9$ & & $n=9$ & $n=16$ & \\
\hline ToC during action (no. of messages) & 20.3 & 17.6 & -2.7 & 15.8 & 25.4 & 9.6 \\
\hline $\begin{array}{l}\text { ToC during action (no. of messages) until action episode mid- } \\
\text { point by time }\end{array}$ & 6.6 & 7.8 & 1.1 & 3.2 & 9.6 & $6.3^{*}$ \\
\hline $\begin{array}{l}\text { ToC during action (no. of messages) until action episode mid- } \\
\text { point by amount of messages }\end{array}$ & 10.7 & 11.4 & 0.7 & 5.1 & 14.4 & $9.3^{*}$ \\
\hline $\begin{array}{l}\text { Fraction of ToC during action until action episode midpoint by } \\
\text { time }\end{array}$ & $40 \%$ & $46 \%$ & $6 \%$ & $21 \%$ & $34 \%$ & $13 \%$ \\
\hline $\begin{array}{l}\text { Fraction of ToC during action until action episode midpoint by } \\
\text { amount of messages }\end{array}$ & $59 \%$ & $67 \%$ & $7 \%$ & $33 \%$ & $52 \%$ & $20 \%$ \\
\hline Number of days with ToC during action & 6.1 & 5.6 & -0.6 & 5.3 & 6.8 & 1.4 \\
\hline Study 2 & $n=9$ & $n=9$ & & $n=8$ & $n=9$ & \\
\hline ToC during action (no. of messages) & 21.3 & 13.9 & -7.4 & 14.1 & 15.2 & 1.1 \\
\hline $\begin{array}{l}\text { ToC during action (no. of messages) until action episode mid- } \\
\text { point by time }\end{array}$ & 7.6 & 6.3 & -1.2 & 3.9 & 4.6 & 0.7 \\
\hline $\begin{array}{l}\text { ToC during action (no. of messages) until action episode mid- } \\
\text { point by amount of messages }\end{array}$ & 8.9 & 9.4 & 0.6 & 7.1 & 9.7 & 2.5 \\
\hline $\begin{array}{l}\text { Fraction of ToC during action until action episode midpoint by } \\
\text { time }\end{array}$ & $45 \%$ & $27 \%$ & $-18 \%$ & $25 \%$ & $27 \%$ & $2 \%$ \\
\hline $\begin{array}{l}\text { Fraction of ToC during action until action episode midpoint by } \\
\text { amount of messages }\end{array}$ & $51 \%$ & $47 \%$ & $-4 \%$ & $54 \%$ & $61 \%$ & $6 \%$ \\
\hline Number of days with ToC during action & 5.2 & 5.0 & -0.2 & 3.4 & 5.4 & 2.1 \\
\hline Pooled data & $n=26$ & $n=18$ & & $n=17$ & $n=25$ & \\
\hline ToC during action (no. of messages, standardized) & -.12 & -.39 & -.27 & .08 & .43 & .35 \\
\hline $\begin{array}{l}\text { ToC during action (no. of messages, standardized) until action } \\
\text { episode midpoint by time }\end{array}$ & .05 & .09 & .03 & -.38 & .14 & $.51^{*}$ \\
\hline $\begin{array}{l}\text { ToC during action (no. of messages, standardized) until action } \\
\text { episode midpoint by amount of messages }\end{array}$ & -.02 & .06 & .08 & -.42 & .26 & $.68^{*}$ \\
\hline Fraction of ToC during action until midpoint by time & $42 \%$ & $36 \%$ & $-5 \%$ & $23 \%$ & $32 \%$ & $9 \%$ \\
\hline $\begin{array}{l}\text { Fraction of ToC during action until midpoint by amount of } \\
\text { messages }\end{array}$ & $56 \%$ & $57 \%$ & $1 \%$ & $42 \%$ & $55 \%$ & $13 \%$ \\
\hline Number of days with ToC during action (standardized) & .06 & -.08 & -.14 & -.40 & .26 & $.66^{\star}$ \\
\hline
\end{tabular}

(ToC: Task-oriented communication, $\Delta$ : High-CA teams minus low-CA teams, ${ }^{*}$ difference between high-

CA and low-CA teams statistically significant at $p<.05$, Mann-Whitney Test) 